\title{
Additive Manufacturing Methods for Producing Hydroxyapatite and Hydroxyapatite-Based Composite Scaffolds: A Review
}

\author{
Anuj Kumar ${ }^{1 *}$, Saeid Kargozar $^{2}$, Francesco Baino ${ }^{3 *}$ and Sung Soo Han ${ }^{1 *}$ \\ ${ }^{1}$ School of Chemical Engineering, Yeungnam University, Gyeongsan-si, South Korea, ${ }^{2}$ Tissue Engineering Research Group, \\ Department of Anatomy and Cell Biology, School of Medicine, Mashhad University of Medical Sciences, Mashhad, Iran, \\ ${ }^{3}$ Department of Applied Science and Technology, Institute of Materials Physics and Engineering, Politecnico di Torino, Turin, \\ Italy
}

Hydroxyapatite (HAp) has been considered for decades an ideal biomaterial for bone repair due to its compositional and crystallographic similarity to bioapatites in hard tissues. However, fabrication of porous HAp acting as a template (scaffold) for supporting bone regeneration and growth has been a challenge to biomaterials scientists. The introduction of additive manufacturing technologies, which provide the advantages of a relatively fast, precise, controllable, and potentially scalable fabrication process, has opened new horizons in the field of bioceramic scaffolds. This review focuses on three-dimensional-printed HAp scaffolds and related composite systems, where the calcium phosphate phase is combined with other ceramics or polymers improving the mechanical properties and/or imparting special extra-functionalities. The main applications of three-dimensional-printed HAp scaffolds in bone tissue engineering are presented and discussed; furthermore, this review also emphasizes the most recent achievements toward the development and testing of multifunctional HAp-based systems combining multiple properties for advanced therapy (e.g., bone regeneration, antibacterial effect, angiogenesis, and cancer treatment).

Keywords: hydroxyapatite, composite, scaffold, additive manufacturing, 3D printing, 4D printing, 5D printing, hard tissue regeneration

\section{INTRODUCTION}

The need for the restoration or replacement of damaged and diseased tissue has significantly increased with the increasing average age of the world population. With this demand, recently, a significant number of materials have been investigated for different applications. Among them, hard tissue regeneration (i.e., bone and dental tissues) is one of the major challenges in healthcare industry (Woesz and Best, 2009). The regeneration of complex tissues in hard tissue engineering needs a multidisciplinary approach and technological aspects.

\section{Hard Tissue Regeneration}

The use of scaffold is an essential factor for hard tissue regeneration by providing desired surface and space for cells to attach, proliferate, migrate, and differentiate to organize a normal bone tissue (Gómez-Lizárraga et al., 2017; Ishack et al., 2017; Kumar et al., 2017b; Farid, 2019). For hard tissue reconstruction, biodegradability, biocompatibility, osteoconductivity, desired pore-interconnected microstructure, and suitable mechanical 
performance are critical characteristics of tissue-engineered scaffolding system (Zhang et al., 2019).

The development of biomaterials in hard tissue regeneration is at a relatively better stage as compared to soft tissue regeneration. In the former case, calcium phosphates, and bioactive glasses may be considered the gold standard for hard tissue regeneration, where these bioceramics exhibit excellent biocompatibility and chemical similarity with hard tissues (i.e., bone and teeth) in mammals (Krishnakumar et al., 2018; Minardi et al., 2019; Sprio et al., 2019). The controlled dissolution of bioceramic implants upon contact with biological solutions provides the in vivo threedimensional (3D) micro-/nanoenvironment with desired ions that improve the growth of native tissue. Therefore, the selection of material type and design for hard tissue regeneration is a great challenge to achieve native $3 \mathrm{D}$ micro-/nanoenvironment (Farid, 2019).

Bioceramics and bioactive glass-based biomaterials exhibit superior biological performance compared to biocompatible but bioinert polymers and have extensively been applied for the clinical repair of bone defects (Sumer et al., 2013; Sasaki et al., 2018). However, due to their brittleness and, hence, poor mechanical performance, these materials are only limited to critical-sized defects of non-load-bearing bones (Daga et al., 2015), and even due to the variation in bone defects and dynamical loading of bones, currently available ceramic materials fail to bridge or fill the anatomical shape and structure of the lost hard tissue, thereby being unable to meet surgical on-demand requirements in a larger critical-sized defects (Jardini et al., 2014).

In the last decades, various processing methods such as solvent casting (Suh et al., 2002), freeze drying (Wu et al., 2010; Kumar et al., 2016a, 2018, 2019), solid-liquid phase separation (Goh and Ooi, 2008), electrospinning (Nandakumar et al., 2010), and gas foaming (Ji et al., 2012) have shown a great potential in fabricating desired scaffolds for a variety of tissues, but these conventional methods fail to control geometry, pore size, and pore interconnectivity of the scaffolding system precisely. Therefore, the achievement of an ideal scaffolding system using conventional methods still is a great challenge in hard tissue repair and regeneration. In this advancement, additive manufacturing (AM) methods have significantly contributed to overcome the limitations of the conventional scaffold processing methods for the treatment of large bone defects and load-bearing applications (Jones, 2012). These AM technologies enable the mold-free fabrication of scaffolds with patient-specific complex characteristics based on medical imaging raw data (Ferlin et al., 2016). AM methods have provided precise anatomical and interconnected design as target-specific hard tissue repair or regeneration with time- and cost-efficient means. Although AM methods exhibit considerable success in orthopedics, there are still certain challenges to be considered (e.g., resolution of printed constructs and mechanical properties) in the optimization of patient-specific scaffolds that may provide 3D micro/nanoenvironment in hard tissue regeneration (Khalyfa et al., 2007; Derby, 2012). A significant number of scaffolds with bone regenerative properties have been investigated in preclinical studies (Xia et al., 2013; Ferlin et al., 2016; Pei et al., 2017), and even few clinical trials already have been performed by addressing translational methods. Moreover, AM methods facilitate the large number of reproducible anatomical geometries of the scaffolds with desired properties that match hard tissues or bone defects in patient-specific manner (Zhang et al., 2019).

\section{ADDITIVE MANUFACTURING TECHNIQUES}

AM of materials has shown a great potential in fabricating patient-specific scaffold using layer-by-layer deposition in a controlled and precise manner. This method was first introduced by Charles W. Hull in 1986, named stereolithography (Hull, 1986), and since then, various types of methods or techniques have been emerged to create detailed or complex $3 \mathrm{D}$ constructs that mimic the internal and external architecture of the targeted (patient-specific) site (Kruth, 1991) to initiate tissue regeneration via cell attachment, proliferation, migration, and differentiation (Maroulakos et al., 2019). Typically, the volumetric model (computer-aided manufacturing) of patient-specific tissue or site is designed from raw anatomical data of medical imaging technology, mainly computed tomography (CT), and magnetic resonance imaging (MRI), and then transferred to a $3 \mathrm{D}$ printer system. Finally, 3D-printed constructs are fabricated using particular 3D printing systems in a layer-by-layer addition of cell-free or cell-encapsulated biomaterial inks (Hollister, 2005; Moreau et al., 2007; Maroulakos et al., 2019). The printing of cell-free or cell-encapsulated biomaterial inks can be categorized as $3 \mathrm{D}$ printing or $3 \mathrm{D}$ bioprinting technology. It is worth pointing out that $3 \mathrm{D}$ printing/bioprinting produces stable designed architectures, while native physiological $3 \mathrm{D}$ micro-/nanoenvironment is dynamic and complex. Therefore, there is the need for the incorporation of time-dependent responsive changes against environmental stimuli/factors in 3Dprinted constructs, which can change form after printing and may provide desired function compatibility during simultaneous tissue regeneration. Recently, the fourth dimension (4D) in terms of "time" was introduced in 2014, and this approach is known as $4 \mathrm{D}$ printing/bioprinting technology (Gladman et al., 2016; Li et al., 2016; Haleem et al., 2019). This provides one more dimension of transformation (shape and function) over time under physical, chemical, and biological stimuli for smart or programmable materials. The $4 \mathrm{D}$-printed biomaterials serve more compatibility with dynamic tissues under regeneration process over stable 3D-printed biomaterials (Javaid and Haleem, 2019; Liu Y. S. et al., 2019). However, this technology still lacks printing complex architectures for regenerating dynamic and complex tissues due to the three-axis printing process. Therefore, most recently, a new five-axis printing technology, called 5D printing, has emerged to print complex and strong architectures with curved surfaces in multiple dimensions compared to 3D/4D-printing technologies. Moreover, 5D-printing technology seems to have the ability to print complex-shaped biomaterials or organs in tissue engineering, especially in orthopedics (Haleem et al., 2019).

A schematic representation of the emergence of printing technology is shown in Figure 1. 


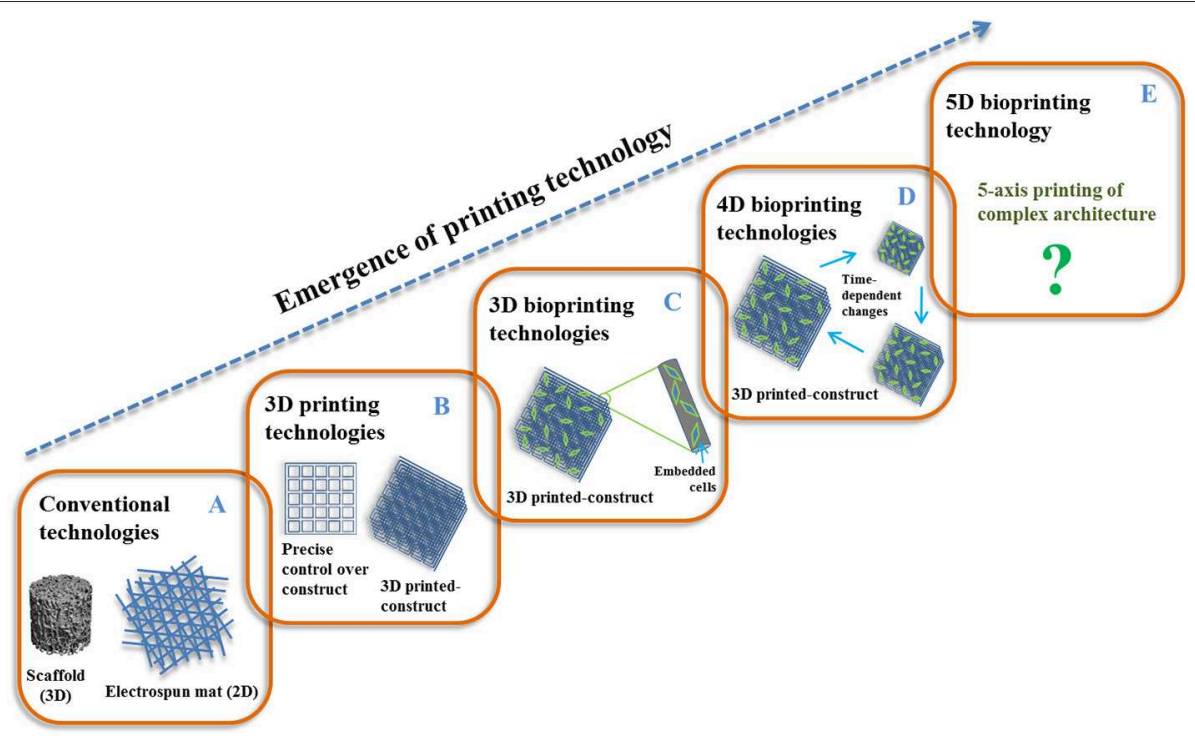

FIGURE 1 | Emergence of printing technology: (A) 2D/3D conventional, (B) 3D printing, (C) 3D bioprinting, (D) 4D bioprinting, and (E) 5D bioprinting.

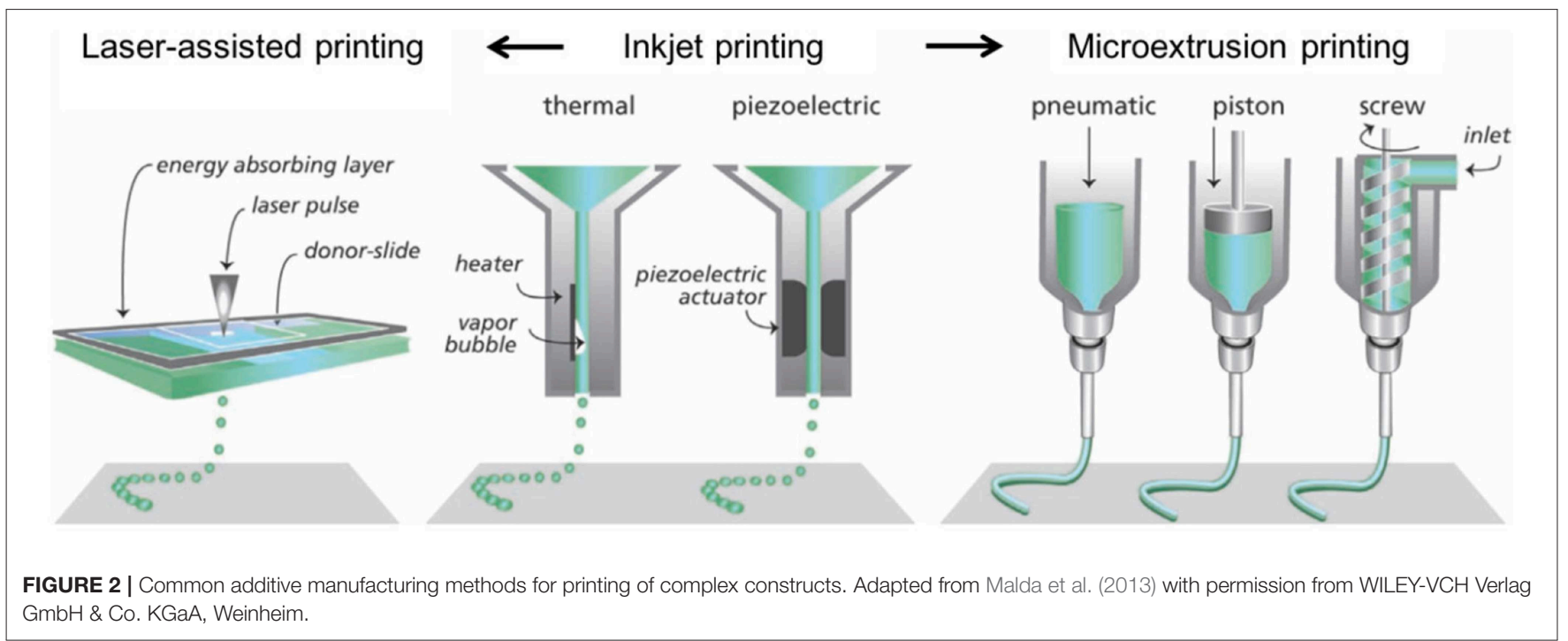

Furthermore, 3D printing/bioprinting can be categorized into three ways: (1) inkjet printing, (2) laser-assisted printing, and (3) microextrusion printing (see Figure 2). All these techniques follow the same coordinated spatial motion while differing in their ink-dispensing mechanisms (Malda et al., 2013). In this case, inkjet printing facilitates the delivery of controlled volumes of liquid (drop-on-demand) to predefined site of the material via different mechanisms (e.g., thermal, acoustic, microvalve) (Saunders et al., 2008). Laser-assisted printing facilitates laser-induced forward technology, where laser pulse is transferred to the absorbing layer (a transparent glass slide coated with laser-energy absorbing layer) and then generates a high-pressure bubble on directed layer of cellfree or cell-encapsulated biomaterial inks and cause to move the inks drop by drop toward the receiving printing surface (e.g., stereolithography, selective laser sintering, or melting) (Guillotin et al., 2010). In addition, microextrusion printing is a robotically controlled dispensing system (e.g., print head, dispensing nozzle, and printing stage), where dispensing nozzle can be mechanical (e.g., piston, screw) or pneumatic (e.g., air, compressed gas) type (Khalil and Sun, 2007; Ozbolat and Hospodiuk, 2016) and facilitates the formation of continuous ink layers or filaments, rather than droplets (e.g., fused deposition modeling, direct-ink writing). In this case, 3D printing of bioceramics, especially hydroxyapatite (HAp), has provided a positive impact on optimal mechanical properties and osteogenic ability in vitro and in vivo (Wu et al., 2012; Wang X. et al., 2019). 


\section{Bioceramics}

Bioceramics are considered often as the inclusion of both amorphous and crystalline inorganic biomaterials. They are typically categorized as synthesized inorganic materials having crystalline structure, which are often called "bioceramics" without any other specification, and synthesized inorganic amorphous materials that are referred to as bioactive glasses. Bioceramics have significantly been used for the repair or replacement of damaged hard tissues for more than 50 years due to their excellent biocompatibility, osteoconductivity/osteoinductivity, and close compositional and mineralogical similarity to the inorganic component of the bone (Hench, 2006; Lin et al., 2014; Kaur et al., 2019; Zhou et al., 2019). In general, bioceramics include a wide range of calcium phosphates based on their $\mathrm{Ca} / \mathrm{P}$ molar ratio and compositions [e.g., amorphous calcium phosphates $(\mathrm{Ca} / \mathrm{P}: 1.2-$ $2.2), \alpha$-tricalcium-phosphate (Ca/P: 1.5 , very quickly resorbable), $\beta$-tricalcium-phosphate $(\mathrm{Ca} / \mathrm{P}: 1.5$, more slowly resorbable compared to the $\alpha$ form), HAp (Ca/P: 1.67, non-resorbable unless in a nanometric form) (Dorozhkin and Epple, 2002; Sadat-Shojai et al., 2013; Kumar et al., 2014, 2017a)], calcium silicates (tricalcium silicates, $\beta$-calcium silicates) (Xu et al., 2008; Yang et al., 2017), bioactive glasses (e.g., silicate-, borate-, borosilicate, phosphate-, doped-, and mesoporous bioactive glasses) (Kumar et al., 2017c; Baino, 2018; Kargozar et al., 2018a,b,c), and bioactive glass-ceramics (partially crystallized materials formed via controlled nucleation and crystallization of glass) (Chen et al., 2006; Suwanprateeb et al., 2009; Caddeo et al., 2019). Calcium phosphate bioceramics have also been successfully proposed for application in contact with soft tissues (Al-Kattan et al., 2012; Celik et al., 2015; Sarda et al., 2016), but this review article is focused on hard tissue regeneration. The schematic representation of the different types of bioceramics is shown in Figure 3.

\section{Hydroxyapatite}

Bone is a complex biocomposite of type I collagen fibrils and HAp $\left[\mathrm{Ca}_{10}\left(\mathrm{PO}_{4}\right)_{6}(\mathrm{OH})_{2}\right]$, where collagen, HAp, and water amounts are 70,20 , and $10 \%$, respectively, of the total bone. The main mineral form in mammals is a hydroxyl-deficient and carbonate-rich apatite (i.e., biological apatite) with $\mathrm{Ca} / \mathrm{P}$ molar ratio <1.67 (Dorozhkin and Epple, 2002; Liu et al., 2013; Sadat-Shojai et al., 2013; Jiang et al., 2015; Szcze et al., 2017). However, HAp found in dentin, enamel, bone, and other natural resources generally does not have this molar ratio because carbonate ions and other impurities replace some phosphate groups $\left(\mathrm{PO}_{4}\right)$, and thereby, bone mineral is more specifically referred to as calcium-deficient carbonated apatite (LeGeros, 2002). Therefore, synthetic HAp possesses similar chemical formula and properties as the main inorganic component (i.e., biological apatite) of both hard tissues (bone and teeth) and has extensively been applied in orthopedic and dental applications for hard tissue repair or regeneration. The use of HAp as a bone substitute includes partial or complete augmentation of bone, filling teeth and bones, or as coating materials on orthopedic and dental implants (Goloshchapov et al., 2019). In the last decades, artificial bone grafts with only HAp or surface coatings with HAp or HAp/polymer-based biomaterials have broadly been developed and investigated. However, the mechanical performance and porous interconnected structure are other important factors, apart from its biocompatibility and biomineralization ability. In addition, HAp-based biomaterials should have proper osteoconductivity and osteointegrative properties (Huang et al., 2011; Xiao Q. et al., 2016; Xiao W. et al., 2016; Szcze et al., 2017). The properties of HAp can be designed and tailored by applying different synthesis routes, which are well-described in the literature (Dorozhkin, 2017). Among the others, a novel synthesis method involves the production of macroporous HAp scaffolds by the pyrolysis of wood: this strategy might be very promising to obtain $3 \mathrm{D}$ hierarchical structures with interconnected porosity for orthopedic surgery (e.g., long bone repair) (Tampieri et al., 2009; Ruffini et al., 2013).

HAp exhibits the slowest degradation rate when compared to other calcium phosphates. HAp shows higher stability in aqueous media compared to other calcium phosphates in the range of 4.2-8.0 $\mathrm{pH}$ values. In addition, the slight imbalance in $\mathrm{Ca} / \mathrm{P}$ molar ratio has significant impact on HAp composition, where $\alpha$-tricalcium phosphate ( $\alpha$-TCP) or $\beta$-TCP may be present if the $\mathrm{Ca} / \mathrm{P}$ molar ratio is lower than 1.67 , and calcium oxide may be present with $\mathrm{HAp}$ phase if $\mathrm{Ca} / \mathrm{P}$ molar ratio is higher than 1.67. This change in HAp phase may affect biological response of the implant adversely in vivo. In certain conditions, it might be beneficial, but it is necessary to match the rate of resorption with that of expected hard tissue regeneration. Calcium phosphate with higher solubility is only limited to be used in defect filling and bone cavity. TCP $(\mathrm{Ca} / \mathrm{P}: 1.5)$ resorbed more rapidly compared to HAp. For example, in the mixture of HAp and TCP [known as biphasic calcium phosphate (BCP)], the higher TCP content in BCP has high dissolution rate. Therefore, the materials with $\mathrm{Ca} / \mathrm{P}$ molar ratio $<1$ are not suitable for biological implantation due to their high solubility (Best et al., 2008).

When implanted, the partial dissolution of $\mathrm{Ca}^{2+}$ ions and $\mathrm{PO}_{4}^{2-}$ ions from HAp leads to the formation of a carbonatedapatite layer via precipitation and intermixing with proteins (Porter et al., 2005). This formed layer as substrate facilitates the proliferation and differentiation of osteoblastic cells, thus preventing the development of a fibrous capsule around the implant material (Rokusek et al., 2005). The quality of the interaction at the bone-implant interface increases with the increased formation of this apatite-like layer (Ducheyne and Qiu, 1999). Therefore, this reactivity (i.e., bioactivity) can be improved by the replacement of phosphate $\left(\mathrm{PO}_{4}^{3-}\right)$ ions with carbonate $\left(\mathrm{CO}_{3}^{2-}\right)$ ions (Barralet et al., 2003) or silicate ions (San Thian et al., 2006). Although higher reactivity is found in BCP, $\alpha$-TCP, and $\beta$-TCP, the limiting factor of their use is the high dissolution speed or resorption of the biomaterial, where dissolution rate and bone ingrowth need to be matched properly (Woesz and Best, 2009).

Moreover, HAp itself has a great potential as bone or teeth filler or as coating biomaterial, but the use of HAp with polymeric system is of even higher interest in producing composite materials with good bioactivity and compressive strength/modulus due to HAp, while toughness, flexibility, and biodegradability are provided by the polymer network. However, 


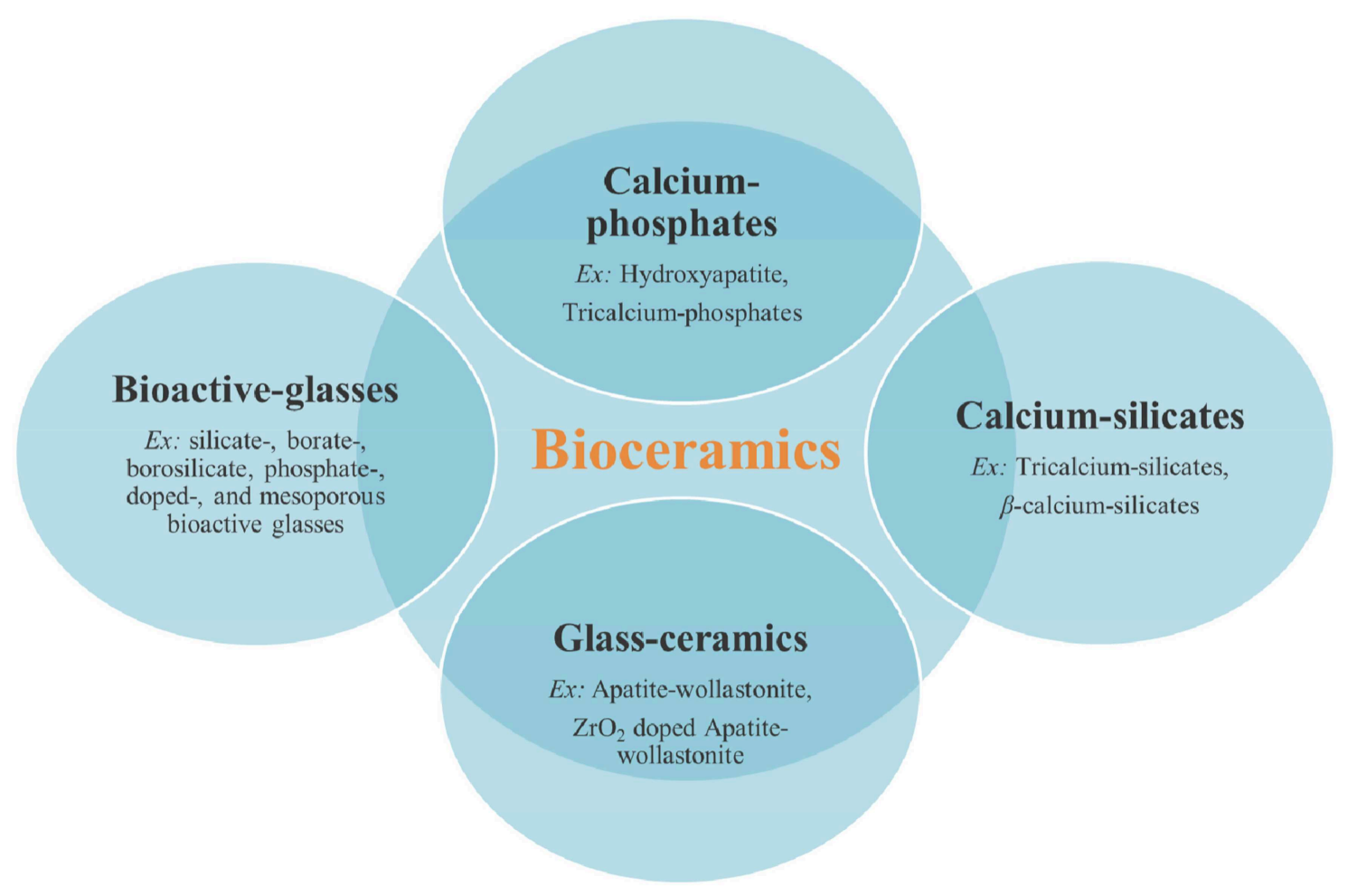

FIGURE 3 | Schematic of the different types of bioceramics.

the major challenge is to obtain homogeneous dispersion of HAp into polymeric matrix and their adhesion to each other (Szcze et al., 2017). HAp has a supportive role in adhesion, growth, proliferation, and differentiation of osteogenesis-related cells. Its excellent biocompatibility has been proven by many previously conducted studies, and HAp-based commercialized products are available on the market for a long time (Dorozhkin, 2017). With the advent of nanotechnology, it was possible to produce HAp particles below $100 \mathrm{~nm}$ having new features such as biodegradability and extra-functionalities. In this regard, $\mathrm{Wu}$ et al. recently reported that HAp nanoparticles possess intrinsic antibacterial effects against both Gram-positive and Gram-negative strains (Wu et al., 2018).

Bacterial infection during bone tissue regeneration is also a major challenge, where this bacterial colonization leads to an infection in tissue followed by implant failure. Treatment using antibiotics is one of the solutions to limit this problem, but the increased bacterial resistance associated to the abuse of antibiotics is another challenge in this area. In this advancement, the introduction of magnesium oxide $(\mathrm{MgO})$ in the HAp was reported to reduce the bacterial growth and biofilm formation in a concentration-dependent fashion; compared to conventional HAp, Mg-doped HAp showed superior antibacterial behavior and biofilm inhibition with equal or above $3 \mathrm{wt}-\%$ of $\mathrm{MgO}$ for Staphylococcus aureus as well as non-toxic behavior and did not facilitate the production of reaction oxygen species by the cells (Coelho et al., 2019). In addition to $\mathrm{Mg}^{2+}$ ions, a series of antibacterial metal ions can be incorporated into HAp structure to reduce the risk of bone infections and to improve bone regeneration. Monovalent $\left(\mathrm{Ag}^{+}\right.$and $\left.\mathrm{F}^{-}\right)$, divalent $\left(\mathrm{Zn}^{2+}\right.$, $\mathrm{Cu}^{2+}$, and $\left.\mathrm{Sr}^{2+}\right)$, and trivalent $\left(\mathrm{Ce}^{3+}\right.$ and $\left.\mathrm{Ga}^{3+}\right)$ ions show antibacterial activities against a broad spectrum of both Grampositive and Gram-negative species (Sahithi et al., 2010; Samani et al., 2013; Gopi et al., 2014; Kargozar et al., 2018c; Law et al., 2018; Pandey et al., 2018; Wang Q. et al., 2019). Bhattacharjee et al. (2019) recently assessed the important effect of dopant site specificity on the antibacterial activity of $\mathrm{Zn}^{2+}$-doped HAp against Escherichia coli and S. aureus. Results clarified that the synthesized specimens exhibited antibacterial activities if $\mathrm{Zn}^{2+}$ ions are substituted in $\mathrm{Ca}^{2+}$ sites of HAp (leaching of the dopant was $\sim 413 \mathrm{ppb}$ ), while they could not act as an antibacterial agent when $\mathrm{Zn}^{2+}$ ions are incorporated in $\mathrm{OH}^{-}$channels of HAp, related to the restricted dopant leaching $(\sim 5.28 \mathrm{ppb})$. In some cases, researchers took benefits from codoping of antibacterial ions with other osteogenic ions (e.g., $\mathrm{Sr}^{2+}$ ions) to promote the bone healing process. For example, Sundarabharathi et al. (2019) could successfully develop $\mathrm{Ce}^{3+}-\mathrm{Sr}^{2+}$ codoped nanoHAp by sol-gel-assisted precipitation method. The obtained results showed that higher antibacterial activity was related to the $\mathrm{Ce}^{3+}$-doped HAp; however, lowered apatite-forming ability and biocompatibility were observed in this group. Although $\mathrm{Sr}^{2+}$-doped samples showed better cytocompatibility, dual doped samples with $\mathrm{Sr}^{2+} / \mathrm{Ce}^{3+}$ simultaneously exhibited antibacterial activity (against $S$. aureus and Pseudomonas 
aeruginosa strains), cytocompatibility, apatite-forming ability, as well as the high thermal stability up to $700^{\circ} \mathrm{C}$, which are all favorable characteristics in bone implant applications. More recently, a ternary dopant system of $\mathrm{ZnO}-, \mathrm{SiO}_{2^{-}}$, and $\mathrm{Ag}_{2} \mathrm{O}-$ substituted plasma sprayed HAp coating was developed by $\mathrm{Vu}$ et al. for orthopedic and dental applications (Vu et al., 2019). The authors added $\mathrm{ZnO}(0.25 \mathrm{wt}-\%)$ to induce osteogenesis, $\mathrm{SiO}_{2}$ (0.5 wt-\%) to induce angiogenesis, and $\mathrm{Ag}_{2} \mathrm{O}$ (2.0 wt-\%) to provide secondary infection control within a plasma-assisted HAp coating. The doped HAp samples showed antibacterial properties against E. coli and S. aureus. The data obtained from 5 and 10 weeks of implantation in Sprague-Dawley rats revealed significant improvements in bone mineralization and total bone formation (32 and 68\%, respectively) in comparison to undoped samples (11 and 55\%, respectively). A complete picture of the synthesis methods and properties of ion-doped HAp can be found elsewhere (Cacciotti, 2019; Hidouri et al., 2019).

Local delivery of antibiotics using HAp has also been suggested as an effective approach in strategies aiming to control bone infections (Safi et al., 2018). On this object, a series of natural chemicals (e.g., peppermint essential oil) and antibiotics (e.g., vancomycin) were loaded into bare and metal-doped HAp (Devanand Venkatasubbu et al., 2011; Yu et al., 2014; Badea et al., 2019). Functionalizing HAp by various chemical agents results in having a prolonged local antibiotic delivery (Leprêtre et al., 2009). In 2018, Lazic et al. functionalized rodlike HAp particles with 5-aminosalicylic acid (5-ASA), resulting in the formation of chemical bonds between HAp surface and adjacent hydroxyl and carboxyl groups from 5-ASA (Lazić et al., 2018). This bonding leads to leave amino groups of 5ASA free to reduce $\mathrm{Ag}^{+}$ions to metallic silver and subsequent antibacterial activity of the samples in a harmless dose to the environment $\left(1 \mathrm{mg} \mathrm{L}^{-1}\right)$.

\section{ADDITIVE MANUFACTURING OF HAP-BASED MATERIALS}

The advantage of AM methods is to produce rapid and consistent manufacturing of target-specific scaffolds that perfectly match with biological complexity of hard tissues (Leukers et al., 2005). The printing of neat HAp scaffolds is very difficult to obtain; they may be processed with sacrificial (e.g., polymers) or other involved materials (e.g., ceramics and bioactive glasses) to produce 3D-printed constructs with controlled architecture and porosity. In this advancement, for hard tissue regeneration, various $\mathrm{AM}$ methods have been used to prepare only HAp or HAp-based 3D-printed constructs, and the produced inks can be categorized into two groups as cell-free and cell-encapsulated biomaterials inks. Therefore, the recent advances by taking only HAp or HAp as one of the components are described in the following sections (as shown in Figure 4).

\section{Only HAp-Based Printing Materials}

Although HAp is extensively being considered for hard tissue regeneration because of its presence in native extracellular matrix $(\mathrm{ECM})$ of bone tissue, very extensive research has not been carried out on pure HAp printed materials due to the lack of bonding and flowability for printing process. Therefore, for the printing of HAp, various types of sacrificial materials have extensively been used. In this case, only HAp-based 3Dprinted complex structures (pore size $=500 \mu \mathrm{m}$ ) with high resolution have successfully been prepared using extrusion-based $3 \mathrm{D}$ printing, where polymeric additive was used as a binder. These scaffolds facilitated good in vitro bone cell (MC3T3-E1) attachment and proliferation (Leukers et al., 2005). In another study, three types of anisotropic 3D-printed HAp cylindrical shapes with interconnected pores as prepared by $3 \mathrm{D}$ printing (Generis, GmbH, Germany) facilitated the differentiation of human multipotent dental neural crest-derived progenitor cells (Fierz et al., 2008). Other authors fabricated two different HAp-based scaffolds using dispense plotting and negative mold method: it was found that dispense-plotted scaffolds exhibited higher cell proliferation, and negative molded scaffolds showed higher cell differentiation (Detsch et al., 2008). Furthermore, an indirect rapid prototyping technique combined with icetemplating (using sacrificial template) or 3D-printed wax mold has been used for producing HAp scaffolds (Charbonnier et al., 2016; Roleček et al., 2019). In addition, the effect of sintering process parameters on 3D-printed HAp scaffolds using selective laser sintering was analyzed, where HAp particles gradually grew and acquired a "spherical-like" shape from the initial "needlelike" shape while still maintaining a nanoscale structure at scanning speed between 200 and $300 \mathrm{~mm} / \mathrm{min}$ (laser power, $50 \mathrm{~W}$; light spot diameter, $4 \mathrm{~mm}$; layer thickness, $0.3 \mathrm{~mm}$ ) (Shuai et al., 2011).

Furthermore, Zhang et al. prepared different types of HApbased powders [nanosized grains powder (NP), 30-50 nm; air-jet milling powders, $10-30 \mu \mathrm{m}$; and spherical powders (SP), 10 $50 \mu \mathrm{m}$ in diameters] that were further used for printing HAp scaffolds using inkjet 3D printing (ALPHA-BP11, Beijing Sunp, Biotech), where poly(vinyl butyral) was used as binder. The results showed good printed porous scaffolds using AP and SP formulations, while NP was found unsuitable for printing due to its dramatic shrinkage behavior (Zhang et al., 2018). Shao et al. prepared 3D-printed porous HAp scaffold (porosity, 52.26\% and pore size, $350 \times 350 \mu \mathrm{m}$ ) with sacrificial polyacrylamide network using extrusion-based $3 \mathrm{D}$ gel printing. In this case, the maximum compressive strength and elastic modulus of sintered HAp scaffold were $16.77 \pm 0.38$ and $492 \pm 11 \mathrm{MPa}$, respectively. In addition, scaffolds showed $10.38 \%$ rate of weight loss after the incubation in Tris- $\mathrm{HCl}$ solution for 5 weeks (Shao et al., 2019). Liu et al. prepared sintered HAp scaffolds using digital light processing method. For printing of HAp scaffold, HAp powder, photopolymer, and liquid sodium polyacrylate were milled, and then, a slurry was prepared. The produced 3Dprinted scaffolds showed good porosity $(49.8 \%)$ with pore size ranging within $300-400 \mu \mathrm{m}$ and compressive strength of 15.25 $\mathrm{MPa}$ along with excellent biocompatibilities and promotion of osteoblast attachment, proliferation, and differentiation (Liu Z. et al., 2019). In addition, Pei et al. introduced a two-step method consisting of extrusion-based $3 \mathrm{D}$ printing and microwave sintering to prepare dual-hierarchical porous scaffolds, where $3 \mathrm{D}$ printing creates a well-controlled macroporous structure 


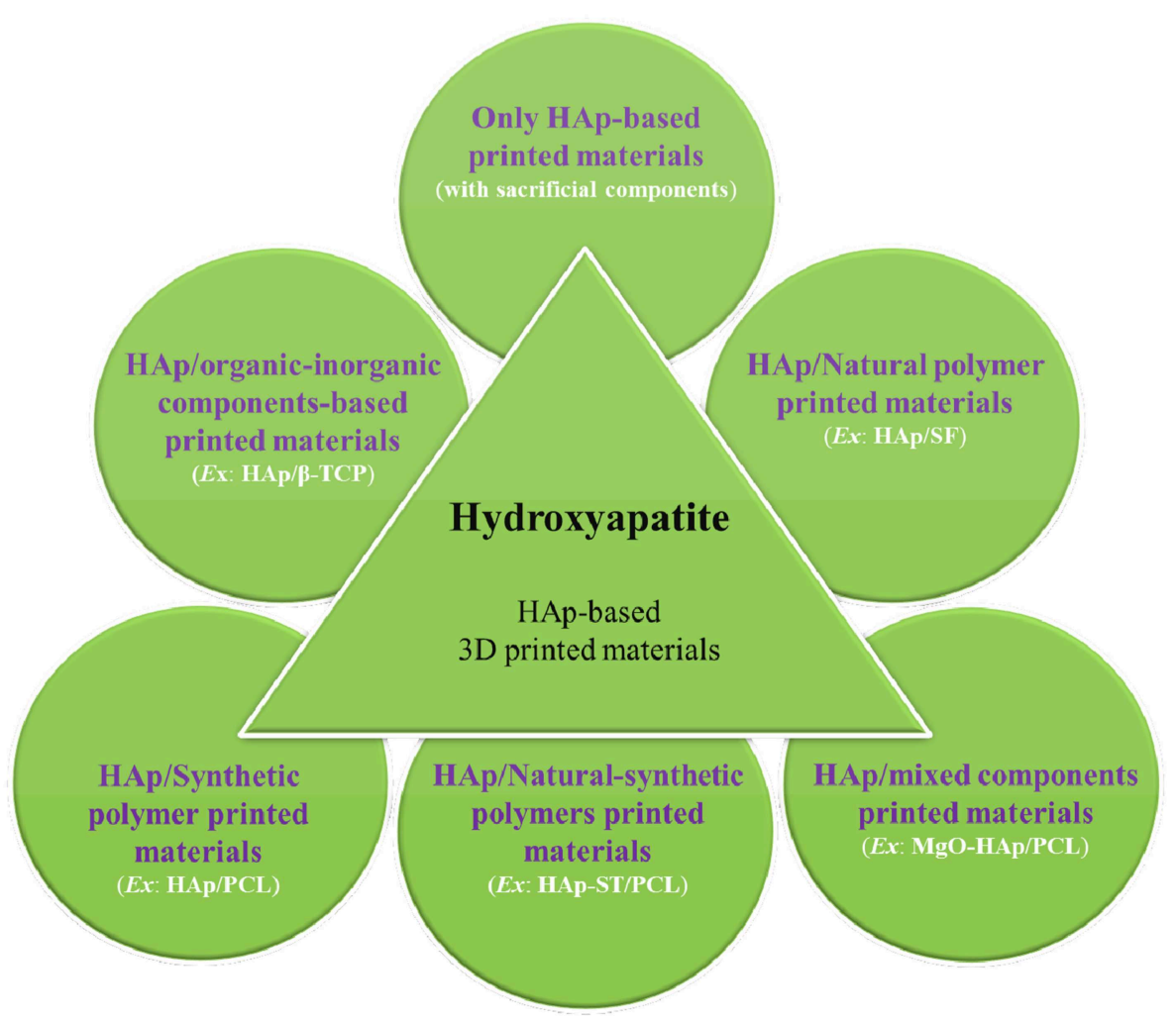

FIGURE 4 | Schematic of the summary of hydroxyapatite (HAp)-based printed materials for hard tissue regeneration.

and microwave-sintering creates a microporous network on the macroporous surface and demonstrated the role of micropores in scaffold-driven bone formation following intramuscular implantation (Pei et al., 2017).

Kumar et al. investigated the effect of two different binder types [sodium alginate (SA) and maltodextrin] in fabricating Hap-printed scaffolds using BioScaffolder 2.1 (GeSiM, Germany), where the optimized printed scaffolds showed porous architecture (up to $74 \%$ porosity). Under compression, both sintered scaffolds showed progressive deformation and delayed fracture, while HAp-SA scaffold exhibited higher compressive strength $(\sim 9.5 \mathrm{MPa})$ than HA-maltodextrin scaffold $(\sim 7.0$ $\mathrm{MPa}$ ) (Kumar et al., 2016b). The addition of SA in the HApbased composite slurry significantly enhanced the quality of the printed and sintered HAp 3D scaffold with controlled porosity and architecture, where HAp-SA scaffolds were printed by a microsyringe extrusion freeforming system (MAM MicroDroplet Jetting, Fochif, China). The sintering temperature had a significant effect on the microstructure, linear shrinkage, and water absorption of HAp/SA printed scaffolds that exhibited rougher surface with submicrometer pores interconnectivity and microparticles on it at a relative lower sintering temperature (i.e., $1,000^{\circ} \mathrm{C}$ ) (Zhou et al., 2015). The addition of PVA to HAp also facilitated the flowability in printing of $3 \mathrm{D}$ scaffolds using a ZPrinter $310+3 \mathrm{D}$ printer (ZCorporation Inc., USA; now owned by $3 \mathrm{D}$ Systems Inc., USA), which allowed varying the microstructure, porosity, and mechanical properties of green scaffolds according to printing along the $X$ - and $Y$-axes. This also affected the removal of PVA degradation products during sintering process. The scaffolds printed in $Y$-axis showed higher compressive strength $(0.88 \pm 0.02 \mathrm{MPa}$, falling within the lower range for cancellous bone) than that of $X$-axis (0.76 $\pm 0.02 \mathrm{MPa}$ ), but traces of PVA degradation products were observed after heat treatment in case of scaffold printed in $Y$-axis. Moreover, HAp scaffolds with non-designed porosity of $55.1 \pm 0.9 \%$ were printed using a commercial $3 \mathrm{D}$ printer (Cox et al., 2015). Furthermore, sintered 3D-printed HAp scaffolds, prepared by 3D plotter (BioScaffolder 2.1, GeSiM, Germany) and coated with ECM deposited by osteoblasts (dECM), demonstrated the role of cell-laid ECM (i.e., natural ECM analog surface) in facilitating biological response to mimic native ECM. In this study, dECM ornamented HAp surface and provided an optimized 3D microenvironment conducive to the $3 \mathrm{D}$ growth of structural tissue with improved expression of prominent proteins, actin, and vinculin, and promoted cell-cell and cell-dECM-HAp interactions. Schematic of 3D-printed scaffold, sintered 3D-printed scaffold of HAp, SEM image of printed scaffold, and high-resolution microCT image of HAp printed-scaffold are shown in Figure 5 (Kumar et al., 2016c).

Catros et al. used an alternative printing method (i.e., laser-assisted bioprinting) and investigated laser printing 

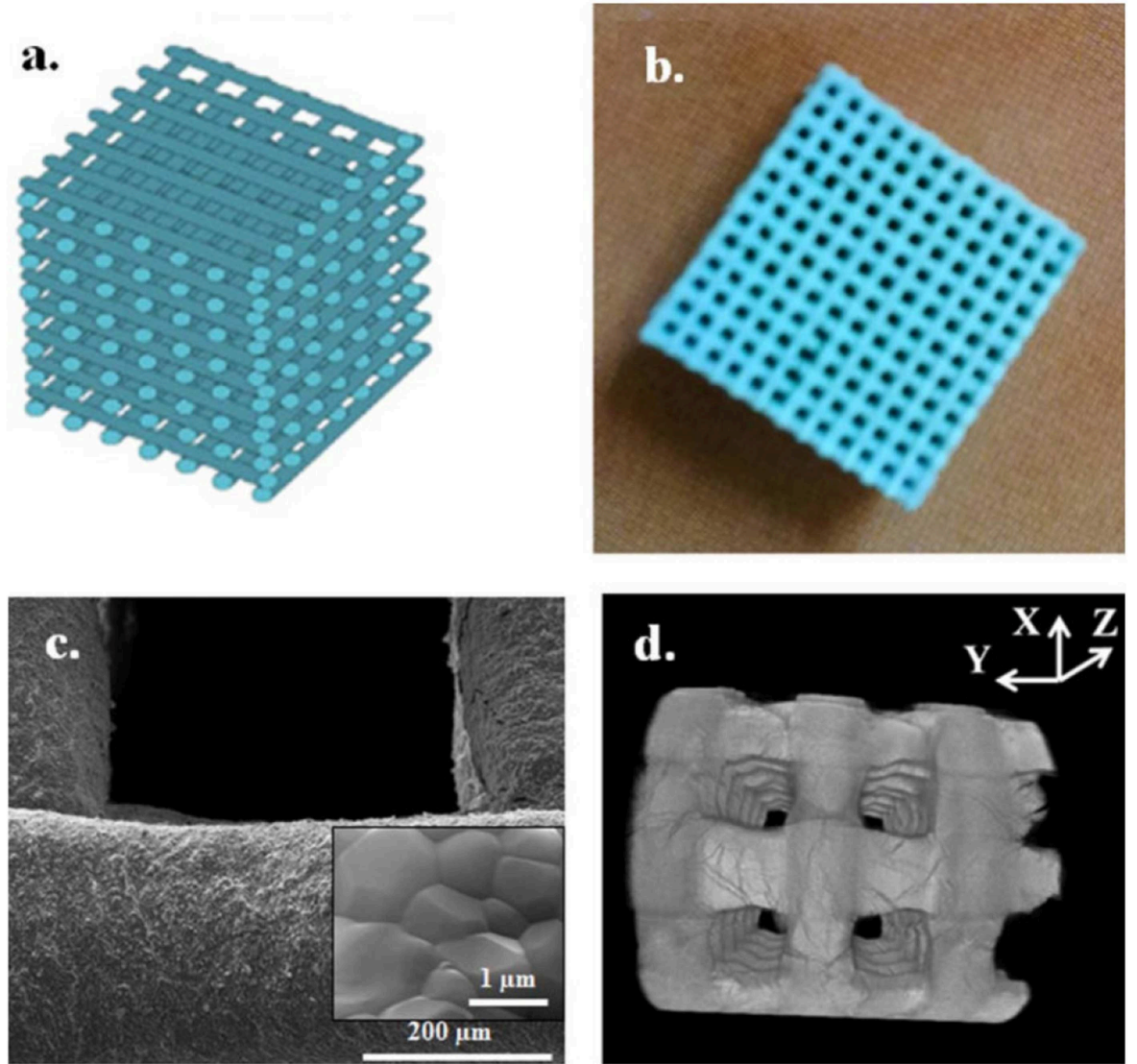

FIGURE 5 | Schematic of 3D-printed scaffold (a), sintered 3D printed-scaffold of HAp with well-defined pores (b), SEM image of printed scaffold showing densified microstructure of the strut surface with approximate grain size of $1 \mu \mathrm{m}$ (inset) (c), and high-resolution micro-CT image of HAp-printed scaffold (d). Reproduced from Kumar et al. (2016c) with permission from Wiley Periodicals, Inc.

parameters for patterning and assembling of bioink composed of HAp and human osteoprogenitors in 2D and 3D systems, where physicochemical behavior of HAp and cell viability, proliferation, and phenotype have not been altered over a time duration of 15 days (Catros et al., 2011). High affinity of HAp with bone morphogenetic proteins (BMPs) exhibited a great potential in bone tissue regeneration (Jun et al., 2013). 3D-printed HAp-based scaffolds prepared using an extrusion-deposition system (MAM-II, Fochif, China) have been developed by the coating of microspheres containing recombinant human BMP (rhBMP-2), collagen, and chitosan for the delivery of rh-BMP-2 to improve human mesenchymal stem cells (hMSCs) cell attachment and proliferation. The in vitro results showed good cell attachment and long-term localized biphasic release of rhBMP-2, and further in vivo results showed improved and desired bone regeneration ability of the coated scaffolds compared to conventional scaffold (Wang et al., 2016).

Although HAp provides excellent biomineralization and osteogenic behaviors, the main disadvantage of only HApbased scaffolds is their non-biodegradability, which limits their confident use in bone regeneration.

\section{HAp-Other Inorganic-Based Materials}

To improve the bioactivity, mechanical properties, osteoconductivity, and osteogenic ability, some other inorganic materials [e.g., graphene nanoflakes, wollastonite (WT)] have been somehow incorporated into HAp. In this case, in situ synthesis of HAp/apatite (AT)-WT glass-ceramic composites was used for 3D printing of scaffolds (Z400, Z Corporation, USA), the mechanical properties of which were characterized at different sintering temperatures. The results showed mean green strength of 1.27 $\mathrm{MPa}$, while strength and flexural modulus after sintering at $1,300^{\circ} \mathrm{C}$ for $3 \mathrm{~h}$ were $76.82 \mathrm{MPa}$ and $34.10 \mathrm{GPa}$, respectively. In addition, 3D-printed HAp/AT-WT composites showed non-toxicity and biomineralization ability (Suwanprateeb et al., 2009). Furthermore, 3D-printed HAp (15\%)/ $\beta$-TCP (85\%) composite scaffolds coated with BMP-2 and dipyridamole (it blocks cellular uptake of adenosine thereby increasing local adenosine levels) have been prepared using robocasting method. Here, an enhanced bone formation and remodeling in $\mathrm{HAp} / \beta$ TCP-dipyridamole and HAp/ $\beta$-TCP-BMP-2 scaffolds was observed (Ishack et al., 2017). In another study, HAp and $\beta$-TCP having two different sizes have been used with calcium sulfate $\left(\mathrm{CaSO}_{4}\right)$ and facilitated the 3D printing of solid constructs using 
a thermal ink-jet 3D printer (Zcorp 310, Z Corporation, UK) with a water-based binder. In this study, effects of HAp, $\beta$-TCP, particle size, and ratio of $\mathrm{HAp} / \mathrm{CaSO}_{4}$ or $\beta-\mathrm{TCP} / \mathrm{CaSO}_{4}$ on $3 \mathrm{D}$ printing process were evaluated. The results showed significant enhancements in printing parameters in the case of HAp or $\beta$-TCP $(30-110 \mu \mathrm{m}) / \mathrm{CaSO}_{4}$ powders compared to HAp or $\beta$-TCP $(<20 \mu \mathrm{m}) / \mathrm{CaSO}_{4}$ powders. Furthermore, $\mathrm{HAp} / \mathrm{CaSO}_{4}$ powders exhibited better results than $\beta-\mathrm{TCP} / \mathrm{CaSO} \mathrm{S}_{4}$ powders, and high-quality $3 \mathrm{D}$-printed solid constructs with a high printing accuracy and an appropriate green compressive strength were fabricated from the optimized powder ratios (Zhou et al., 2014).

Jakus and Shah in 2017 prepared cell-free 3D-printed constructs composed of HAp microspheres [hyperelastic bone $(\mathrm{HB})]$ and $3 \mathrm{D}$ graphene nanoflakes [3D graphene (3DG)] materials. In this study, three different printing inks were prepared as $\mathrm{HB}, 3 \mathrm{DG}$, and $\mathrm{HB}-3 \mathrm{DG}$ (1:1) hybrid systems. The resulting $\mathrm{HB}-3 \mathrm{DG}$ printing inks in $3 \mathrm{D}$-printed structures using 3D Bioplotter (EnvisionTEC, GmbH, Germany) showed mixed properties of these two components while maintaining their printability, flexibility, and electrical conductivity. In addition, HB-3DG-printed construct showed good cell viability and proliferation with MSCs and, furthermore, significantly upregulated both osteogenic and neurogenic gene expression over 14 days. However, HB-3DG-printed constructs exhibited microstructural, mechanical, and electrical (to some extent) properties more similar to 3DG compared to HB. The developed printed constructs may serve for transition zones between two distinct tissue types by mimicking the characteristic gradients present in native multitissue interfaces as complex tissues (Jakus and Shah, 2017). Digital images of HB, 3DG, and HB-3DG, their corresponding SEM images of the fiber surfaces along with cross-sections and fiber porosity (\%) are given in Figure 6.

\section{HAp/Polymer-Based Printing Materials}

Pure HAp-based 3D-printed constructs exhibit average geometrical options, low mechanical performance, and flexibility, which limit their confident use for hard tissue regeneration. Therefore, various methods have been developed for 3D printing of HAp/polymer-based materials, which actually exhibit promising results both in vitro and in vivo. In this case, polymeric material provides the excellent flexibility and biodegradability (e.g., hydrolysis, cellular, or enzymatic degradation) in designing scaffolding materials. Therefore, HAp has been widely combined with natural and/or synthetic polymers for a variety of hard tissue engineering applications (Zhang et al., 2019).

\section{HAp/Natural Polymer-Based Materials}

Ardelean et al. in 2018 prepared 3D-printed material composed of HAp/collagen (HAp/COLL) using 3D Bioplotter (EnvisionTEC), and the results showed that the printed material exhibited a good cellular response in culture medium similar to standard culture medium (Ardelean et al., 2018). Huang et al. (2019) prepared HAp/silk fibroin (SF) nanocomposite particles using in situ precipitation and then used this material for the fabrication of 3D-printed scaffolds by 3D Bioplotter (EnvisionTEC GmbH, Germany), using SA as a paste binder. The obtained 3D-printed scaffolds showed good porosity (70\%) with interconnected pores $(-400 \mu \mathrm{m})$ and relatively high compressive strength (>6 MPa). In addition, all scaffolds showed good in vitro biomineralization activity in simulated body fluid (SBF) while maintaining steady $\mathrm{pH}$ of the medium and cell attachment and penetration. It was also observed that an increased amount of SF in HAp/SF nanocomposite led to better cell proliferation, alkaline phosphatase activity, and sustained release of drug over a 5-day test duration (Huang et al., 2019). In another study, calcium phosphate paste has been prepared by involving HAp (4 wt-\%) as a component and, separately, chitosan/dextran sulfate microparticles encapsulating bovine serum albumin (BSA) or vascular endothelial growth factor were prepared. Freeze-dried microparticles and calcium phosphate were mixed easily and printed in water-saturated atmosphere (humidity) using BioScaffolder 2.1 (GeSiM mbH, Grosserkmannsdorf, Germany) to avoid early loss of loaded proteins. The produced printed humidity-set scaffolds exhibited good cytocompatibility, and maintained bioactivity of vascular endothelial growth factor has been established by indirect and direct culture analysis with endothelial cells (Akkineni et al., 2015).

\section{HAp/Synthetic Polymer-Based Materials}

Dental or tooth regeneration using cell delivery confronts translational obstacles. Synthetic polymers have been used extensively with HAp to print HAp-based scaffolds due to their easy structural manipulability, flexibility, and versatile mechanical performances. In the recent times, several studies involving HAp with poly(L-lactide) (PLA) (Russias et al., 2007; Ronca et al., 2013; Liu et al., 2016), poly(lactide-co-glycolide) (PLGA), poly(epsilon-caprolactone) (PCL) (Russias et al., 2007; Yao et al., 2015; Gómez-Lizárraga et al., 2017; Kim et al., 2018; Vella et al., 2018), and poly(propylene fumarate) (PPF) (Lee et al., 2009; Trachtenberg et al., 2016, 2017) have been reported in the literature. Russias et al. produced PLA or PCL/HAp (70 wt-\%) as hybrid organic/inorganic scaffolding constructs with controlled porous microstructures using robotic-assisted deposition (3D inks, Stillwater, OK, USA) at room temperature. For comparison, PLA/6P53B glass (70 wt-\%) (c) printed scaffolds have also been printed. The produced printed constructs did not show significant degradation after 20 days incubation in SBF. Furthermore, all printed scaffolds showed an apatite globular formation on their surface (Russias et al., 2007). Schematic of the robocasting process, the digital and synchrotron X-ray computed tomographical images of printed scaffolds, and their SEM images, including after 20 days incubation in SBF, are shown in Figure 7.

In another study, Duan et al. prepared scaffolds composed of carbonated HAp (CHAp) and PLA using selective laser sintering method, where CHAp/PLA scaffolds showed similar cellular response compared with neat PLA scaffold (Duan et al., 2010). In another study, PLA matrix has been reinforced with carbonatite HAp particles (cHAp) in different ratios (100/0, 95/05, 90/10, and 80/20) and printed using fused deposition modeling (FDM). The results showed low interaction between PLA and cHAp, and the compressive strength and moduli of elasticity of the scaffolds were observed to be reduced compared to neat PLA scaffold. However, PLA/cHAp scaffold (80/20) 

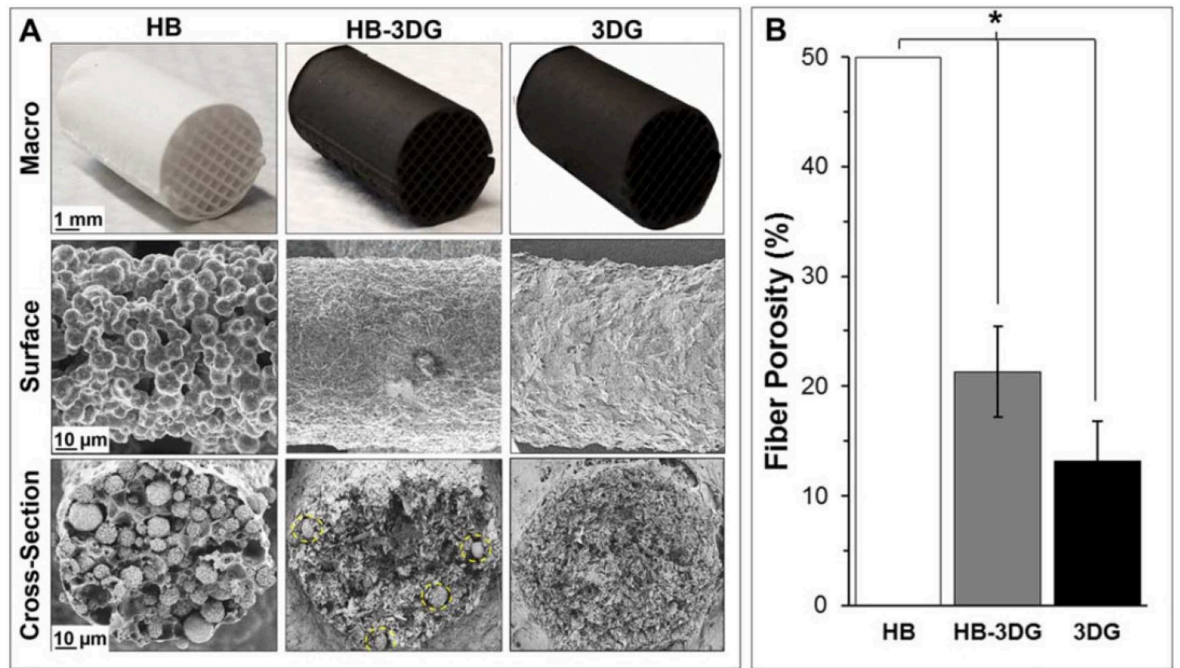

FIGURE 6 | (A) Digital images of HB, 3DG, and HB-3DG and their corresponding SEM images of the fiber surfaces along with cross-sections. Yellow-dotted circle lines represent hydroxyapatite (HAp) particles within the graphene matrix in HB-3DG. (B) Porosity (\%) within HB, 3DG, and HB-3DG-printed fibers ( ${ }^{*} p<0.05$, error bar represents standard deviation). Reproduced from Jakus and Shah (2017) with permission from Wiley Periodicals, Inc.

showed better properties than other compositions (Oladapo et al., 2019). Furthermore, thermomechanical response of HAp/PLAprinted scaffolds using CubePro Trio (3D Systems, Inc) by fused filament fabrication has been analyzed. The results showed reversible PLA phase transformation at $\sim 60^{\circ} \mathrm{C}$ and irreversible above $90^{\circ} \mathrm{C}$, and the scaffolds exhibited an enhanced shape memory effect and mechanical properties with the incorporation of HAp (Sui et al., 2019). Furthermore, HAp/PLA scaffolds with recovery stress of 3.0 $\mathrm{MPa}$ have been prepared using CubePro Trio (3D Systems, Inc) by fused filament fabrication, where HAp served as nucleation centers and provided an additional rigid fixed phase that reduced molecular mobility. The results showed that the shape recovery of these HAp particles inhibited crack growth during compression-heating-compression cycles and $15 \%$ HAp/PLA scaffold with $98 \%$ shape recovery could be used as self-fitting bone implants (Senatov et al., 2016).

The incorporation of HAp into PCL matrix showed good compatibility and printability. In addition, HAp/PCL blends showed shear-thinning behavior and higher elastic modulus than TCP/PCL blends at low frequencies for the same ceramic content (Huang and Bártolo, 2018). Xia et al. prepared HAp/PCL printed scaffold using selective laser sintering method. The resulted scaffolds showed well-ordered macropores and interconnected micropores with good porosity $(\sim 70-78 \%)$, as well as good compressive strengths $(1.38-3.17 \mathrm{MPa})$ for bone repair. HAp/PCL-printed scaffolds exhibited excellent in vitro biocompatibility (even more bioactive) and increased release rate of rhBMP-2 than PCL scaffolds. In vivo study demonstrated that HAp/PCL-printed scaffolds showed improved efficiency of bone formation than PCL scaffolds when implanted in rabbit femur defects for 3, 6, and 9 weeks (Xia et al., 2013).

In another study, granular hybrid material composed of calcium phosphate microparticles (Ca-polyP-MP) and PCL has been prepared and liquefied by short-term heating to $100^{\circ} \mathrm{C}$ to print tissue-like scaffolds using 3D Bioplotter (EnvisionTEC, Gladbeck; Germany). The results showed suitable biomechanical properties matching those of trabecular and cortical bone with morphogenic activity. In addition, 3D-printed scaffold exhibited apatite formation and the growth of human bone-related SaOS2 cells and upregulated the cell-migration-inducing chemokine stromal-derived factor-1a (SDF-1a) (i.e., steady-state expression) (Neufurth et al., 2017). The shifted pattern in 3D-printed HAp/PCL scaffolds produced using a melt-extrusion-based 3D plotter had better cell attachment as well as lower compressive modulus than the 3D-printed PCL and HAp/PCL scaffolds without the shifted pattern. In addition, the cell proliferation and differentiation on the $3 \mathrm{D}$-printed scaffolds was observed in the following order: shift-patterned HAp/PCL > HAp/PCL > PCL (Park et al., 2011). Furthermore, in HAp/polymer composites, generally, polymer makes a thin-film coating over the HAp particles on the outer surface of the scaffolds and inhibits the original biomineralization characteristics of HAp particles. To prevent this behavior, Cho et al. proposed an alkaline erosion method to expose the HAp particles covered by a thin film of polymer (i.e., PCL) and prepared 3D-printed HAp/PCL scaffolds using melt-extrusion-based 3D printing followed by alkaline erosion. In this study, the proposed alkaline erosion showed little effect on the structure and mechanical properties of the $3 \mathrm{D}$-printed scaffold and improved the cell proliferation and biomineralization (Cho et al., 2019a).

The autogenous vascularization in bone grafts is often required for the reconstruction of both small and large complex craniofacial bone defects. For this consideration, Kuss et al. (2017) extracted the stromal vascular fraction from the adipose tissues by maintaining the phenotypes and the growth of endothelial lineage cells and then used them in the $3 \mathrm{D}$ bioprinting of bioinks (HAp/PCL hydrogel + cells) using a nozzle-deposition system ( $\mathrm{GmbH}$ EnvisionTEC 3D 

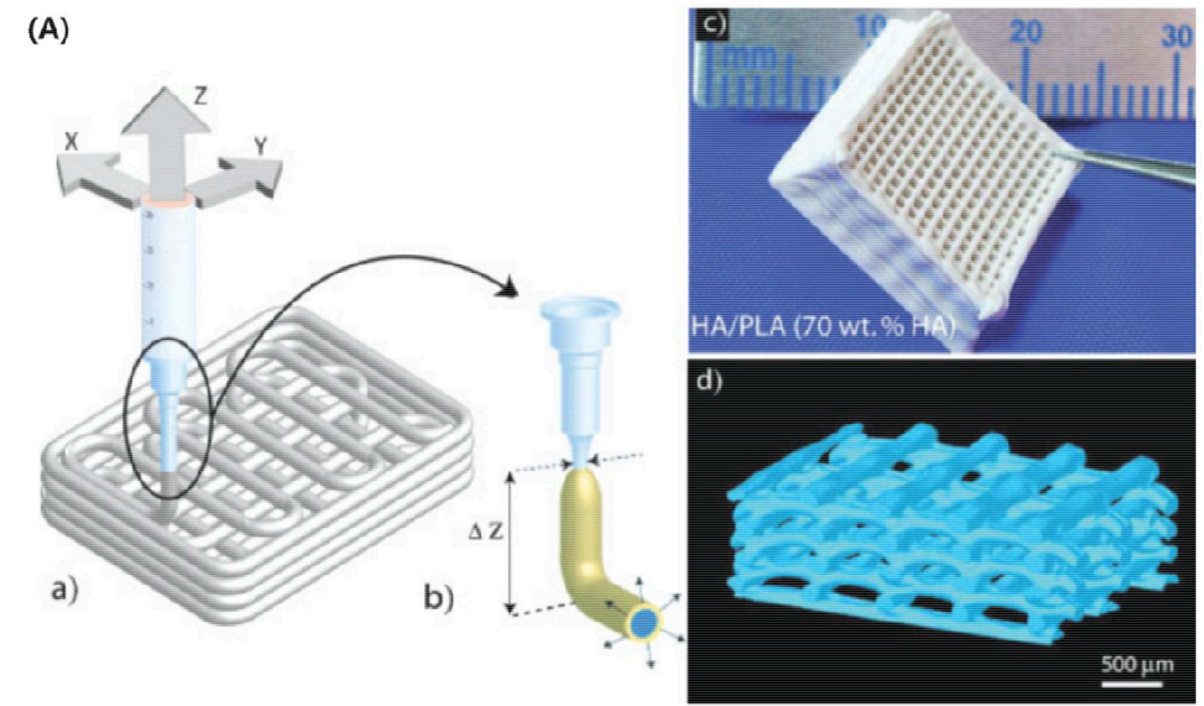

(B)

(C)
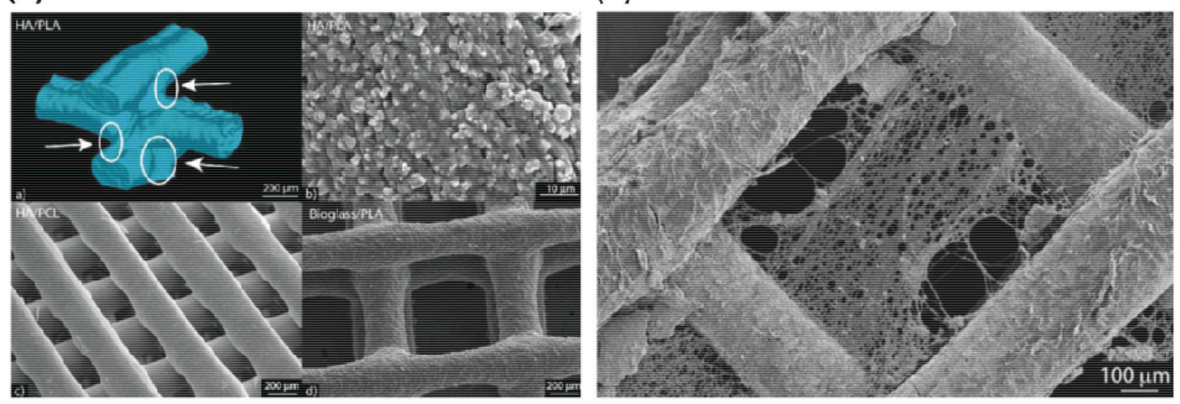

FIGURE 7 | (A) Schematic of the robocasting process showing liquid flow via the nozzle (a), inks tend to swell after leaving the nozzle during printing and form a solid skin printed lines after evaporation of solvent (b), digital image of PLA/HAp (70 wt-\%) printed scaffold of 17 layers (c), and 3D reconstructed image of PLA/HAp (70 wt-\%) grid obtained by synchrotron X-ray computed tomography (d). (B) 3D reconstructed image of the junction between PLA/HAp (70 wt-\%) printed filaments obtained by synchrotron X-ray computed tomography (a), SEM image showing homogenous distribution of HAp particles in PLA/HAp (70 wt-\%) printed filament at higher magnification (b), homogenous PCL/HAp (70 wt-\%), and PLA/6P53B glass (70 wt-\%) printed filaments (c). (C) SEM image of PCL/HAp (70 wt-\%) printed scaffold after 20 days incubation in SBF, where degradation on the surface of printed scaffold can be seen clearly. A nozzle having an internal diameter of $410 \mu \mathrm{m}$ has been used for all printed scaffolds. Reproduced from Russias et al. (2007) with permission from Wiley Periodicals, Inc.

Bioplotter ${ }^{\mathrm{TM}}$ ) followed by conditioning in either normoxia or hypoxia. In this case, vascularization-related gene expression was promoted in short-term hypoxic conditioning, while cell viability and vascularization were impaired in long-term hypoxia. In addition, in vitro and in vivo formation of microvessels by integration with existing host vasculature was promoted without affecting osteogenic differentiation of stromal vascular fraction cells due to short-term conditioning (Kuss et al., 2017).

Kim et al. prepared HAp/PCL scaffolds using 3D bioprinting and implanted them without cell delivery. Here, in vivo analysis in rat incisor scaffold, where SDF-1 and bone morphogenetic protein-7 were provided in the scaffold microchannels, showed the formation of tooth-like structures and periodontal integration using the homing cells. In addition, SDF-1 and bone morphogenetic protein-7 significantly recruited the more endogenous cells and elaborated higher angiogenesis compared to growth factor-free control scaffolds (Kim et al.,
2010). Furthermore, HAp (7\%)-PPF/diethyl fumarate scaffolds were prepared using microstereolithography method, and these scaffolds with micro-/nanoscale morphology exhibited better cell attachment and proliferation than that of PPF/diethyl fumarate scaffolds (Lee et al., 2009). Trachtenberg et al. investigated the extrusion-based 3D printing of PPF in full-factorial design by evaluating four factors such as concentration, printing pressure, printing speed, and fiber spacing (Trachtenberg et al., 2016) and further printed PPF incorporated with HAp (Trachtenberg et al., 2017).

\section{HAp/Natural-Synthetic Polymer-Based Materials}

There is a paucity of studies on this kind of tricomposite biomaterials in the current literature. In a very recent report, Koski et al. printed scaffolds composed of HAp, gelatinized corn 
starch (ST), and PCL (HAp-ST/PCL) using a slurry-extrusionbased solid-freeform fabricator. In this study, the incorporation of ST (as natural binder) showed high mechanical properties (from $4.07 \pm 0.66$ to $10.35 \pm 1.10 \mathrm{MPa}$ ) more closely to resemble to cancellous bone. In addition, an improved in vitro human fetal osteoblast cell attachment and proliferation was observed on scaffolds in the presence of ST and PCL together (Koski et al., 2018).

\section{HAp/Mixed Components Printed Materials}

HAp has also been used as coating material for bioactive glasses. Motealleh et al. in 2017 robocasted 45S5 Bioglass (BG) scaffolds using a 3D printer (A3200, 3D inks, Stillwater, OK, USA) and coated them by HAp/PCL nanocomposite to improve the mechanical properties (compressive strength and fracture toughness) up to 200\% (Motealleh et al., 2017). Touri et al. prepared 3D-printed scaffolds composed of $60 \%$ HAp and $20 \%$ $\beta$-TCP using robocasting method (a direct-write assembly), and further, the produced scaffolds were coated with various ratios of an oxygen releasing agent (i.e., calcium peroxide) encapsulated within PCL matrix, which was used for in situ production of oxygen at the implanted sites. The results showed sustained release of oxygen (dependent on the concentration) that could promote bone ingrowth with enhanced osteoblast cell viability and proliferation under hypoxic conditions (Touri et al., 2018).

Kim et al. printed PLGA/ $\beta$-TCP scaffolds with simple and complex design using FDM and coated them with HAp. The HAp-coated or uncoated PLGA/ $\beta$-TCP scaffolds, as implanted in rabbit femoral unicortical bone defects, were shown to have good biocompatibility and integration with the host bone. All implant sites showed normal-appearing tissues without swelling and tissue necrosis; no clinical complications (i.e., infection, wound failure, or exudate) have been detected at the implant sites (Kim et al., 2012).

Chen et al. developed 3D-printed composite scaffolds composed of HAp, gelatin, chitosan, and carboxymethyl cellulose using a Regenovo Bioprinter (Regenovo Biotechnology, China); these scaffolds showed $\sim 600 \mu \mathrm{m}$ macroporosity and the ultimate compressive strength of $14.3 \mathrm{MPa}$ for optimized composite scaffold (Chen et al., 2019a). In another study, a trilayered scaffold has been fabricated using extrusion-based multinozzle $3 \mathrm{D}$ printing for the regeneration of cartilage and subchondral bone simultaneously. In such trilayered scaffolds, top layer is only methacrylated gelatin (GelMA, 15\%) for cartilage, interfacial layer is of both HAp (3\%) and GelMA (20\%), and the bottom layer is HAp (3\%) and GelMA (30\%) for subchondral bone. The results based on in vitro study showed good biocompatibility with bone marrow MSCs and in vivo repair of rabbit osteochondral defect using this trilayered scaffold, the neo-tissues integrated better with surrounding tissues, surface of joint was observed to be smoother, and more cartilage-specific ECM and collagen type II were formed compared to monophasic GelMA implant (Liu J. et al., 2019). In another study, a Si-doped HAp/gelatin (SiHAp-GE)-based composite slurry was used to fabricate porous constructs by nozzle-deposition system ( $\mathrm{GmbH}$ EnvisionTEC 3D Bioplotter ${ }^{\mathrm{TM}}$ ) (Martínez-Vázquez et al., 2015). Liu et al. incorporated strontium $(\mathrm{Sr})$ in HAp and used this material to print 3D SrHAp/PCL scaffolds using melt-blending filament in motor-assisted microsyringe (MAM). 3D-printed SrHAp/PCL composite scaffolds showed a sustained release of $\mathrm{Sr}$ and $\mathrm{Ca}$ ions, as well as significant cell proliferation and induced higher levels of BMSCs differentiation compared to neat PCL and HAp/PCL scaffolds. Furthermore, in vivo study showed promotion of bone regeneration significantly after the incorporation of SrHAp in the PCL scaffold (Liu D. et al., 2019).

Roh et al. reported the incorporation of HAp along with $\beta$ TCP into PLGA matrix for producing 3D-printed scaffolds (pore size, $\sim 300 \mu \mathrm{m}$ ) using 3D Bioextruder, which then underwent surface etching by oxygen plasma treatment. In this study, the increased surface roughness and hydrophilicity of 3Dprinted scaffold due to oxygen plasma treatment showed improved osteoblastic MC3T3-E1 cell attachment, proliferation, and differentiation, and the differentiation was further improved by the incorporation of HAp/ $\beta$-TCP in the $3 \mathrm{D}$-printed PLGA scaffold (Roh et al., 2016). Furthermore, the incorporation of Bio-Oss, decellularized bone matrix, and TCP in PCL matrix showed statistically lower print quality using FDM process than PCL and HAp/PCL scaffolds, but Bio-Oss/PCL and decellularized bone/PCCL hybrid materials exhibited more advantages for bone healing over HAp/PCL or TCP/PCL hybrid materials (Nyberg et al., 2017). Roh et al. also reported that addition of magnesium oxide (MgO)/HAp into PCL matrix and plasma-treated $\mathrm{MgO}$ HAp/PCL-printed scaffolds prepared by a 3D Bioextruder were associated to improved osteoblastic MC3T3-E1 cell attachment, proliferation, and differentiation (Roh et al., 2017).

In another study, carbon nanotubes (CNTs, 0-10 wt-\%) have been incorporated in a HAp/PCL composite system and 3D-printed CNTs-HAp/PCL scaffold by a nozzle-deposition system (GmbH EnvisionTEC 3D Bioplotter ${ }^{\mathrm{TM}}$ ) were prepared at room temperature and investigated. These 3D-printed scaffolds showed bone-like interconnected porous network (450$700 \mu \mathrm{m})$, good bioactivity, and the capability of promoting cell attachment and spreading; specifically, CNTs (2 wt-\%)HAp/PCL scaffolds exhibited the best combination of mechanical properties (i.e., compressive strength, $4 \mathrm{MPa}$ ) and electrical conductivity (Gonçalves et al., 2016). Figure 8 presents the schematic representation of the slurry preparation and printed scaffolds composed of PCL (50 wt-\%) and HAp (40 wt-\%) with or without CNT (10 wt-\%), and their SEM image, including TEM image of composite system.

\section{POTENTIAL AND SIGNIFICANCE IN HARD TISSUE REGENERATION AND DRUG DELIVERY APPLICATIONS}

HAp is one of the widely used materials regarding repair and regeneration of injured bones, either in the form of micro- and nanosized particle or as 3D scaffolds. Up to now, numerous studies have been conducted to evaluate the effects of HApbased 3D-printed scaffolds on the structural and functional behaviors of differentiated cells (osteoblasts and osteoclasts) and undifferentiated cells (bone-marrow derived MSCs); it could promote osteogenesis-related genes and thereby enhance 


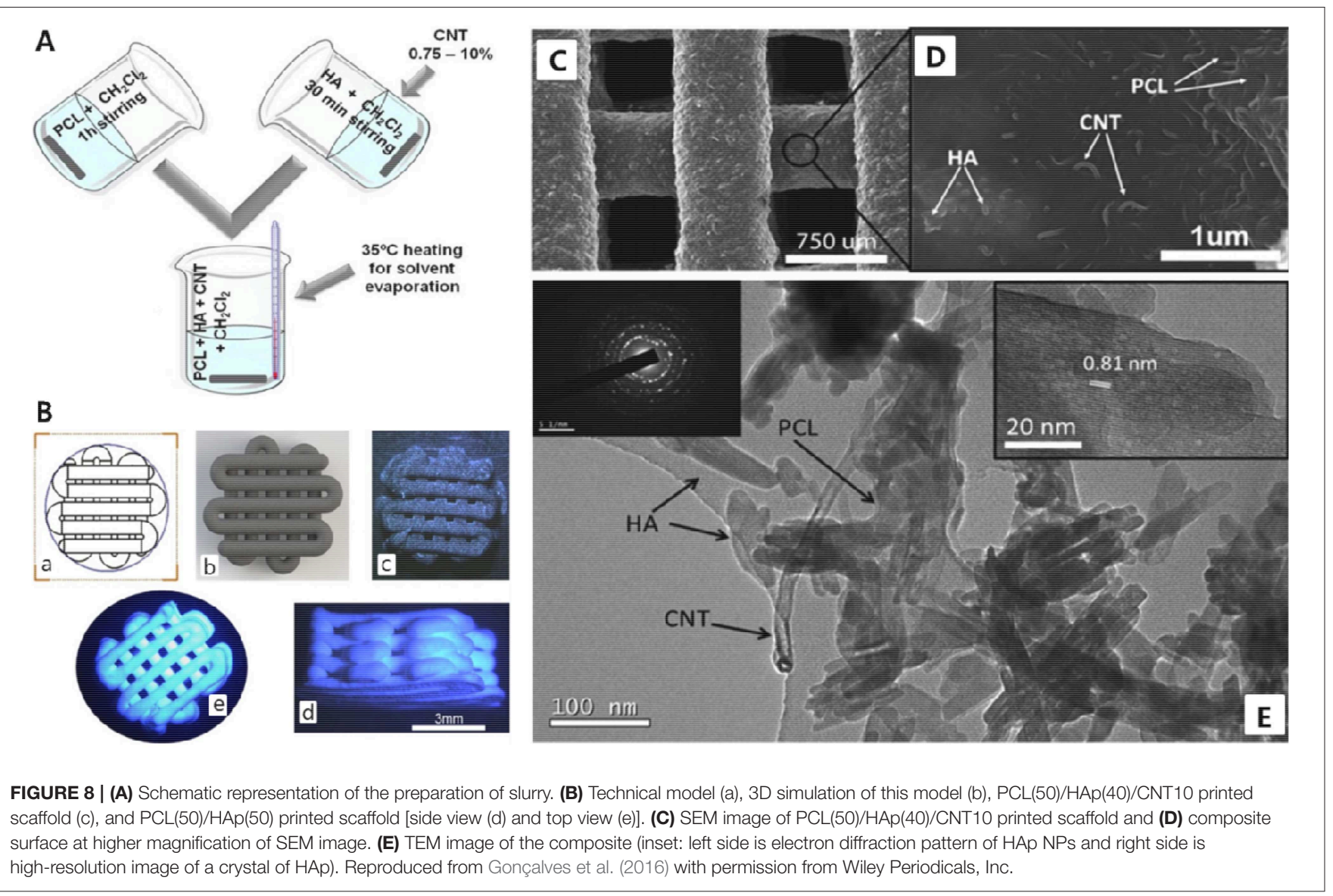

osteoblast differentiation (Gonçalves et al., 2016; Zheng et al., 2017; Huang et al., 2019; Li N. et al., 2019). As an illustration, 3D-printed HAp ceramics obtained by digital light processing showed the ability to improve the growth and proliferation of MC3 T3-E1 osteoblast precursor cell line as well as facilitate the cell adhesion and migration in vitro (Zeng et al., 2018). Furthermore, in vivo experimental studies have proven that $3 \mathrm{D}$ printed scaffolds made of HAp and its composites could act as excellent bone replacements, thanks to proper osteoconductivity (Cho et al., 2019b; Sha et al., 2019). It should be mentioned that 3D-printed HAp scaffolds are also found as competent vehicles to deliver osteogenic growth factors like bone morphogenetic protein-2 for improving in vivo bone regeneration (Chen G. et al., 2019).

Although HAp chemical composition is similar to the mineral phase of native bone tissue, it was observed that stoichiometric HAp has no other valuable trace ions (e.g., $\mathrm{Si}^{4+}, \mathrm{Sr}^{2+}$, and $\mathrm{Mg}^{2+}$ ), which are regularly found in natural hard tissues (Yilmaz et al., 2018). Therefore, the synthesis and use of HAp doped with therapeutic ions in the form of 3D scaffolds have been carried out to make more effective HAp-based bone substitutes (Luo et al., 2018; Chen et al., 2019b). Recently, 3D-printed PCL/Srdoped HAp scaffolds were used for enhanced bone regeneration in the cranial defect of rats (Liu Y. S. et al., 2019). The in vitro experiments showed a sustained release of $\mathrm{Sr}$ from the scaffolds, resulting in higher alkaline phosphatase activity and overexpression of osteo-related genes (collagen 1, osteocalcin, osteopontin, and RUNX2). In vivo implantation of these 3Dprinted PCL/Sr-doped HAp materials led to accelerated bone regeneration in comparison to $3 \mathrm{D}$-printed Sr-free PCL and PCL/HAp scaffolds. Other metallic dopants (e.g., silver) have also been incorporated into HAp to prepare 3D-printed scaffolds with more biological capabilities such as antibacterial activity (Suvannapruk et al., 2013).

In addition to ionic dopants, other parameters related to HAp particles and their 3D-printed scaffolds could be effective in directing cell fate (Ribeiro et al., 2010; Costa-Rodrigues et al., 2012; Li Q. et al., 2019) including pore architecture and surface topography of the scaffolds (orientation and roughness) (Roh et al., 2016, 2017; Barba et al., 2018). For example, it has been reported that the use of nanosized HAp particles in 3D-printed bone composite scaffolds (PCL/nanosized HAp particle) results in an enhanced adhesion, viability, and osteogenic differentiation of hMSCs when compared with the counterparts containing microsized HAp particles (Domingos et al., 2017).

The fabrication and use of composites based on HAp and polymers have achieved great success in terms of bone tissue engineering applications as a result of improved physicochemical and mechanical properties (Ramesh et al., 2018). Up to now, a huge number of experimental studies have confirmed the 
effectiveness of adding HAp to natural and synthetic biopolymers as a mean to improve the bone healing process; in fact, some recent works focus on $3 \mathrm{D}$ printing of HAp/biopolymers for obtaining osteoconductive composite scaffolds. On this object, 3D-printed scaffolds composed of PLGA and HAp were prepared and grafted by hydroxypropyltrimethyl ammonium chloride chitosan with the aim of obtaining multifunctional systems with osteoconductive and antibacterial properties (Yang et al., 2016). The results showed that HAp-containing constructs grafted with hydroxypropyltrimethyl ammonium chloride chitosan support cell adhesion, proliferation, spreading, and osteogenic differentiation, and exhibited antibacterial effects, good neovascularization, and tissue integration both in vitro and in vivo.

As a potential drug delivery carrier, HAp shows favorable characteristics including biocompatibility, tailorable size, active surface, and ease of modification (Martínez-Vázquez et al., 2015; Syamchand and Sony, 2015; Li H. et al., 2019). Therefore, HAp in different shapes or forms is recognized as a promising vehicle to deliver different bioactive molecules to accelerate bone tissue regeneration or for other therapeutic purposes. The applicability of doped HAp nanostructures and magnetic HAp has also been successfully verified for drug delivery strategies both in vitro and in vivo (Mondal et al., 2018). Antiresorptive drugs (e.g., alendronate), anticancer drugs (e.g., cisplatin), antibiotics (e.g., gentamycin), and other small molecules (proteins, DNA, and RNA) are the main categories of cargoes, which were loaded in and delivered from HAp (Kolmas et al., 2016). For example, macroporous HAp was used as a suitable carrier for the oral delivery of carvedilol, a poorly water-soluble drug (Zhao et al., 2011). Over time and along with the advent of $3 \mathrm{D}$ printing technology, controlled release of various bioactive molecules (e.g., rhBMP-2) from 3D-printed porous HAp scaffolds was highlighted as a novel DDS for bone regeneration (Wang et al., 2016; Chen G. et al., 2019).

Several experimental methods and approaches, including lowtemperature 3D powder direct printing process, have been developed and used to effectively load drugs into 3D-printed HAp scaffolds (Gbureck et al., 2007). It is worth mentioning that a few parameters such as microstructure, specific surface area, and coatings could affect drug loading efficacy of calcium phosphates like HAp (Water et al., 2015; Suvannapruk and Suwanprateeb, 2018). In 2019, Chen et al. reported that layer-by-layer coating of porous 3D-printed HAp composite scaffolds using chitosan and sodium hyaluronate could improve the sustained release of drugs from the scaffolds. They used two molecules, i.e., rhodamine B and BSA, to study drug release ability of the 3D-printed scaffolds; the results clarified that the size of molecules used can also affect the release rate (the larger molecule BSA shows faster release) (Chen et al., 2019c).

\section{CONCLUSIONS AND FUTURE PERSPECTIVES}

AM-based methods-especially 3D printing/bioprinting-have shown a great potential in tissue engineering applications due to their customization ability (e.g., spatial and temporal control) in making patient-specific tissue-engineered structures or grafts (as per anatomical design). Considerable outcomes based on tissue-specific printed constructs fabricated by different AMbased methods have been achieved for hard tissue regeneration in vitro and in vivo.

Although extensive research studies have been carried out to improve the desired properties of printed architectures of HApbased materials, especially load-bearing implants, according to specific hard tissue type and/or organ, there is still a great challenge in the formulation, development, and processing of HAp-based bioinks to achieve desired properties under native hard tissue environment. Therefore, native-like tissue regeneration (i.e., implant integration, gradual remodeling, vascularization, and maturation) using bioprinted implants needs proper optimization of the design and development of bioinks, which includes accounting for print-related problems associated to materials, cells, processing parameters (pre/postprinting), etc. (Singh and Ramakrishna, 2017). For this, a comprehensive understanding of the biomaterials, cells, printing methods, and in vivo biological environment is needed. The risk of nozzle clogging and the achievement of mechanically stable architectures are also critical factors during printing process. In addition, the printing of more complex 3D architectures using multimaterial, different cell types, and multiprinting methods to achieve in vivo cellular diversity and functionality is a major concern (Derakhshanfar et al., 2018).

Furthermore, clinical translation of the 3D-bioprinted biomaterials still remains a great challenge in the field of tissue engineering. Therefore, there is a need of extensive and significant research activities to understand structural, chemical, physicomechanical, rheological, biological, and immunological properties using a multidisciplinary effort in tissue engineering field. $4 \mathrm{D}$ printing, intended as $3 \mathrm{D}$ printing of programmable materials, facilitates gradual changes in their shape and functionally with time as fourth dimension (Gladman et al., 2016; Li et al., 2016). Moreover, in orthopedics, complex and strong implants with curved surfaces are extremely important for proper hard tissue regeneration. Recently, in addition to 3Dand $4 \mathrm{D}$-printing technologies, a so-called " $5 \mathrm{D}$ printing" strategy has emerged as a promising technology. This 5D-printing technology uses a five-axis system to print complex architectures in multiple dimensions. A strong structure with curved layers could be printed by $5 \mathrm{D}$ printing, whereas $3 \mathrm{D}$ printing only could print structures with flat surface (Haleem et al., 2019). In the near future, there are promising prospects with $3 \mathrm{D}$, $4 \mathrm{D}$, and $5 \mathrm{D}$ printing technologies and their combinations in orthopedics and may lead to significant impacts in clinical and translational research.

\section{AUTHOR CONTRIBUTIONS}

$\mathrm{AK}$ and $\mathrm{FB}$ initiated and formulated this project. $\mathrm{AK}, \mathrm{SK}, \mathrm{FB}$, and $\mathrm{SH}$ contributed equally in searching the literature, writing, and finalizing the manuscript. 


\section{FUNDING}

The writing of this review article was supported by the 2019 Yeungnam University research grant and

\section{REFERENCES}

Akkineni, A. R., Luo, Y., Schumacher, M., Nies, B., Lode, A., and Gelinsky, M. (2015). 3D plotting of growth factor loaded calcium phosphate cement scaffolds. Acta Biomater. 27, 264-274. doi: 10.1016/j.actbio.2015.08.036

Al-Kattan, A., Girod-Fullana, S., Charvillat, C., Ternet-Fontebasso, H., Dufour, P., Dexpert-Ghys, J., et al. (2012). Biomimetic nanocrystalline apatites: emerging perspectives in cancer diagnosis and treatment. Int. J. Pharm. 423, 26-36. doi: 10.1016/j.ijpharm.2011.07.005

Ardelean, I. L., Gudovan, D., Ficai, D., Ficai, A., Andronescu, E., Albu-Kaya, M. G., et al. (2018). Collagen/hydroxyapatite bone grafts manufactured by homogeneous/heterogeneous 3D printing. Mater. Lett. 231, 179-182. doi: 10.1016/j.matlet.2018.08.042

Badea, M. L., Iconaru, S. L., Groza, A., Chifiriuc, M. C., Beuran, M., and Predoi, D. (2019). Peppermint essential oil-doped hydroxyapatite nanoparticles with antimicrobial properties. Molecules 24:2169. doi: 10.3390/molecules 24112169

Baino, F. (2018). Bioactive glasses-when glass science and technology meet regenerative medicine. Ceram. Int. 44, 14953-14966. doi: 10.1016/j.ceramint.2018.05.180

Barba, A., Maazouz, Y., Diez-Escudero, A., Rappe, K., Espanol, M., Montufar, E. B., et al. (2018). Osteogenesis by foamed and 3D-printed nanostructured calcium phosphate scaffolds: effect of pore architecture. Acta Biomater. 79, 135-147. doi: 10.1016/j.actbio.2018.09.003

Barralet, J. E., Fleming, G. J. P., Campion, C., Harris, J. J., and Wright, A. J. (2003). Formation of translucent hydroxyapatite ceramics by sintering in carbon dioxide atmospheres. J. Mater. Sci. 38, 3979-3993. doi: 10.1023/A:1026258515285

Best, S. M., Porter, A. E., Thian, E. S., and Huang, J. (2008). Bioceramics: past, present and for the future. J. Eur. Ceram. Soc. 28, 1319-1327. doi: 10.1016/j.jeurceramsoc.2007.12.001

Bhattacharjee, A., Gupta, A., Verma, M., Murugan, P. A., Sengupta, P., Matheshwaran, S., et al. (2019). Site-specific antibacterial efficacy and cyto/hemo-compatibility of zinc substituted hydroxyapatite. Ceram. Int. 45, 12225-12233. doi: 10.1016/j.ceramint.2019.03.132

Cacciotti, I. (2019). Multisubstituted hydroxyapatite powders and coatings: the influence of the codoping on the hydroxyapatite performances. Int. J. Appl. Ceram. Technol. 6, 1864-1884. doi: 10.1111/ijac.13229

Caddeo, S., Caddeo, S., Mattioli-Belmonte, M., Cassino, C., Barbani, N., Dicarlo, M., et al. (2019). Newly-designed collagen/polyurethane bioartificial blend as coating on bioactive glass-ceramics for bone tissue engineering applications. Mater. Sci. Eng. 96, 218-233. doi: 10.1016/j.msec.2018.11.012

Catros, S., Fricain, J.-C., Guillotin, B., Pippenger, B., Bareille, R., Remy, M., et al. (2011). Laser-assisted bioprinting for creating on-demand patterns of human osteoprogenitor cells and nano-hydroxyapatite. Biofabrication 3:025001. doi: 10.1088/1758-5082/3/2/025001

Celik, T., Yuksel, D., Kosker, M., Kasim, R., and Simsek, S. (2015). Vascularization of coralline versus synthetic hydroxyapatite orbital implants assessed by gadolinium enhanced magnetic resonance imaging. Curr. EyeRes. 40, 346-353. doi: 10.3109/02713683.2014.922192

Charbonnier, B., Laurent, C., and Marchat, D. (2016). Porous hydroxyapatite bioceramics produced by impregnation of 3D-printed wax mold: Slurry feature optimization. J. Eur. Ceram. Soc. 36, 4269-4279. doi: 10.1016/j.jeurceramsoc.2016.06.005

Chen, G., Sun, Y., Lu, F., Jiang, A., Subedi, D., Kong, P., et al. (2019). A three-dimensional (3D) printed biomimetic hierarchical scaffold with a covalent modular release system for osteogenesis. Mater. Sci. Eng. 2019:109842. doi: 10.1016/j.msec.2019.109842

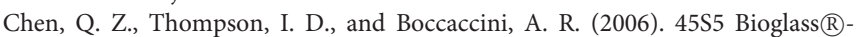
derived glass-ceramic scaffolds for bone tissue engineering. Biomaterials 27, 2414-2425. doi: 10.1016/j.biomaterials.2005.11.025 by the Basic Science Research Program through the National Research Foundation of Korea (NRF) funded by the Ministry of Education, Science and Technology (Grant No. 2017R1D1A3B03036276).
Chen, S., Shi, Y., Luo, Y., and Ma, J. (2019c). Layer-by-layer coated porous 3D printed hydroxyapatite composite scaffolds for controlled drug delivery. Colloids Surfaces Biointerf. 179, 121-127. doi: 10.1016/j.colsurfb.2019.03.063

Chen, S., Shi, Y., Zhang, X., and Ma, J. (2019a). 3D printed hydroxyapatite composite scaffolds with enhanced mechanical properties. Ceram. Int. 45, 10991-10996. doi: 10.1016/j.ceramint.2019.02.182

Chen, S., Shi, Y., Zhang, X., and Ma, J. (2019b). Biomimetic synthesis of Mgsubstituted hydroxyapatite nanocomposites and three-dimensional printing of composite scaffolds for bone regeneration. J. Biomed. Mater. Res. 107, 2512-2521. doi: 10.1002/jbm.a.36757

Cho, Y. S., Choi, S., Lee, S. H., Kim, K. K., and Cho, Y. S. (2019a). Assessments of polycaprolactone/hydroxyapatite composite scaffold with enhanced biomimetic mineralization by exposure to hydroxyapatite via a 3D-printing. Eur. Polym. J. 113, 340-348. doi: 10.1016/j.eurpolymj.2019.02.006

Cho, Y. S., Quan, M., Lee, S. H., Hong, M. W., Kim, Y. Y., and Cho, Y. S. (2019b). Assessment of osteogenesis for 3D-printed polycaprolactone/hydroxyapatite composite scaffold with enhanced exposure of hydroxyapatite using rat calvarial defect model. Compos. Sci. Technol. 184:107844. doi: 10.1016/j.compscitech.2019.107844

Coelho, C. C., Araújo, R., Quadros, P. A., Sousa, S. R., and Monteiro, F. J. (2019). Antibacterial bone substitute of hydroxyapatite and magnesium oxide to prevent dental and orthopaedic infections. Mater. Sci. Eng. C 97, 529-538. doi: $10.1016 /$ j.msec.2018.12.059

Costa-Rodrigues, J., Fernandes, A., Lopes, M. A., and Fernandes, M. H. (2012). Hydroxyapatite surface roughness: complex modulation of the osteoclastogenesis of human precursor cells. Acta Biomater. 8, 1137-1145. doi: 10.1016/j.actbio.2011.11.032

Cox, S. C., Thornby, J. A., Gibbons, G. J., Williams, M. A., and Mallick, K. K. (2015). 3D printing of porous hydroxyapatite scaffolds intended for use in bone tissue engineering applications. Mater. Sci. Eng. C 47, 237-247. doi: 10.1016/j.msec.2014.11.024

Daga, D., Mehrotra, D., Mohammad, S., Singh, G., and Natu, S. M. (2015). Tentpole technique for bone regeneration in vertically deficient alveolar ridges: a prospective study. J. Oral Biol. Craniofacial Res. 5, 92-97. doi: 10.1016/j.jobcr.2015.03.001

Derakhshanfar, S., Mbeleck, R., Xu, K., Zhang, X., Zhong, W., and Xing, M. (2018). 3D bioprinting for biomedical devices and tissue engineering: a review of recent trends and advances. Bioact. Mater. 3, 144-156. doi: 10.1016/j.bioactmat.2017.11.008

Derby, B. (2012). Printing and prototyping of tissues and scaffolds. Science 338, 921-926. doi: 10.1126/science. 1226340

Detsch, R., Uhl, F., Deisinger, U., and Ziegler, G. (2008). 3D-Cultivation of bone marrow stromal cells on hydroxyapatite scaffolds fabricated by dispenseplotting and negative mould technique. J. Mater. Sci. Mater. Med. 19, 1491-1496. doi: 10.1007/s10856-007-3297-x

Devanand Venkatasubbu, G., Ramasamy, S., Ramakrishnan, V., and Kumar, J. (2011). Nanocrystalline hydroxyapatite and zinc-doped hydroxyapatite as carrier material for controlled delivery of ciprofloxacin. 3 Biotech 1, 173-186. doi: 10.1007/s13205-011-0021-9

Domingos, M., Gloria, A., Coelho, J., Bartolo, P., and Ciurana, J. (2017). Threedimensional printed bone scaffolds: the role of nano/micro-hydroxyapatite particles on the adhesion and differentiation of human mesenchymal stem cells. Proc. Inst. Mech. Eng. Part H 231, 555-564. doi: 10.1177/0954411916680236

Dorozhkin, S.V. (2017). Hydroxyapatite and Other Calcium Orthophosphates: General Information and History. New York, NY: Nova Science Publishers.

Dorozhkin, S. V., and Epple, M. (2002). Biological and medical significance of calcium phosphates. Angew. Chemie Int. Ed. 41, 3130-3146. doi: 10.1002/1521-3773(20020902)41:17<3130::AID-ANIE3130>3.0.CO;2-1

Duan, B., Wang, M., Zhou, W. Y., Cheung, W. L., Li, Z. Y., and Lu, W. W. (2010). Three-dimensional nanocomposite scaffolds fabricated via selective 
laser sintering for bone tissue engineering. Acta Biomater. 6, 4495-4505. doi: 10.1016/j.actbio.2010.06.024

Ducheyne, P., and Qiu, Q. (1999). Bioactive ceramics: the effect of surface reactivity on bone formation and bone cell function. Biomaterials 20, 2287-2303. doi: 10.1016/S0142-9612(99)00181-7

Farid, S. B. H. (2019). Hard tissue engineering applications. Bioceram. Mater. Sci. Eng. 2019, 119-158. doi: 10.1016/B978-0-08-102233-7.00005-7

Ferlin, K. M., Prendergast, M. E., Miller, M. L., Kaplan, D. S., and Fisher, J. P. (2016). Influence of 3D printed porous architecture on mesenchymal stem cell enrichment and differentiation. Acta Biomater. 32, 161-169. doi: 10.1016/j.actbio.2016.01.007

Fierz, F. C., Beckmann, F., Huser, M., Irsen, S. H., Leukers, B., Witte, F., et al. (2008). The morphology of anisotropic 3D-printed hydroxyapatite scaffolds. Biomaterials 29, 3799-3806. doi: 10.1016/j.biomaterials.2008.06.012

Gbureck, U., Vorndran, E., Müller, F. A., and Barralet, J. E. (2007). Low temperature direct 3D printed bioceramics and biocomposites as drug release matrices. J. Control. Release 122, 173-180. doi: 10.1016/j.jconrel.2007.06.022

Gladman, A. S., Matsumoto, E. A., Nuzzo, R. G., Mahadevan, L., and Lewis, J. A. (2016). Biomimetic 4D printing. Nat. Mater. 15, 413-418. doi: $10.1038 /$ nmat 4544

Goh, Y. Q., and Ooi, C. P. (2008). Fabrication and characterization of porous poly(l-lactide) scaffolds using solid-liquid phase separation. J. Mater. Sci. Mater. Med. 19, 2445-2452. doi: 10.1007/s10856-008-3366-9

Goloshchapov, D. L., Lenshin, A. S., Savchenko, D. V., and Seredin, P. V. (2019). Importance of defect nanocrystalline calcium hydroxyapatite characteristics for developing the dental biomimetic composites. Results Phys. 13:102158. doi: 10.1016/j.rinp.2019.102158

Gómez-Lizárraga, K. K., Flores-Morales, C., Del Prado-Audelo, M. L., ÁlvarezPérez, M. A., Piña-Barba, M. C., and Escobedo, C. (2017). Polycaprolactoneand polycaprolactone/ceramic-based 3D-bioplotted porous scaffolds for bone regeneration: a comparative study. Mater. Sci. Eng. C 79, 326-335. doi: 10.1016/j.msec.2017.05.003

Gonçalves, E. M., Oliveira, F. J., Silva, R. F., Neto, M. A., Fernandes, M. H., Amaral, M., et al. (2016). Three-dimensional printed PCL-hydroxyapatite scaffolds filled with CNTs for bone cell growth stimulation. J. Biomed. Mater. Res. Part B Appl. Biomater. 104, 1210-1219. doi: 10.1002/jbm.b.33432

Gopi, D., Ramya, S., Rajeswari, D., Karthikeyan, P., and Kavitha, L. (2014). Strontium, cerium co-substituted hydroxyapatite nanoparticles: synthesis, characterization, antibacterial activity towards prokaryotic strains and in vitro studies. Colloids Surfaces A Physicochem. Eng. Asp. 451, 172-180. doi: 10.1016/j.colsurfa.2014.03.035

Guillotin, B., Souquet, A., Catros, S., Duocastella, M., Pippenger, B., Bellance, S., et al. (2010). Laser assisted bioprinting of engineered tissue with high cell density and microscale organization. Biomaterials 31, 7250-7256. doi: 10.1016/j.biomaterials.2010.05.055

Haleem, A., Javaid, M., and Vaishya, R. (2019). 5D printing and its expected applications in Orthopaedics. J. Clin. Orthop. Trauma. 10, 809-810. doi: $10.1016 /$ j.jcot.2018.11.014

Hench, L. L. (2006). The story of bioglass®. J. Mater. Sci. Mater. Med. 17, 967-978. doi: $10.1007 / \mathrm{s} 10856-006-0432-\mathrm{z}$

Hidouri, M., Dorozhkin, S. V., and Albeladi, N. (2019). Thermal behavior, sintering and mechanical characterization of multiple ion-substituted hydroxyapatite bioceramics. J. Inorg. Organomet. Polym. Mater. 29, 87-100. doi: 10.1007/s10904-018-0969-6

Hollister, S. J. (2005). Porous scaffold design for tissue engineering. Nat. Mater. 4, 518-524. doi: 10.1038/nmat1421

Huang, B., and Bártolo, P. J. (2018). Rheological characterization of polymer/ceramic blends for 3D printing of bone scaffolds. Polym. Test. 68, 365-378. doi: 10.1016/j.polymertesting.2018.04.033

Huang, T., Fan, C., Zhu, M., Zhu, Y., Zhang, W., and Li, L. (2019). 3Dprinted scaffolds of biomineralized hydroxyapatite nanocomposite on silk fibroin for improving bone regeneration. Appl. Surf. Sci. 467, 345-353. doi: 10.1016/j.apsusc.2018.10.166

Huang, Y.-T., Imura, M., Nemoto, Y., Cheng, C.-H., and Yamauchi, Y. (2011). Block-copolymer-assisted synthesis of hydroxyapatite nanoparticles with high surface area and uniform size. Sci. Technol. Adv. Mater. 12:045005. doi: 10.1088/1468-6996/12/4/045005
Hull, C. W. (1986). Apparatus for Production of Three-Dimensional Objects by Stereolithography. US Pat. 4,575,330.

Ishack, S., Mediero, A., Wilder, T., Ricci, J. L., and Cronstein, B. N. (2017) Bone regeneration in critical bone defects using three-dimensionally printed $\beta$-tricalcium phosphate/hydroxyapatite scaffolds is enhanced by coating scaffolds with either dipyridamole or BMP-2. J. Biomed. Mater. Res. Part B Appl. Biomater. 105, 366-375. doi: 10.1002/jbm.b. 33561

Jakus, A. E., and Shah, R. N. (2017). Multi and mixed 3D-printing of graphenehydroxyapatite hybrid materials for complex tissue engineering. J. Biomed. Mater. Res. Part A 105, 274-283. doi: 10.1002/jbm.a.35684

Jardini, A. L., Larosa, M. A., Maciel Filho, R., de Carvalho Zavaglia, C. A., Bernardes, L. F., Lambert, C. S., et al. (2014). Cranial reconstruction: 3D biomodel and custom-built implant created using additive manufacturing. J. Cranio-Maxillofacial Surg. 42, 1877-1884. doi: 10.1016/j.jcms.2014. 07.006

Javaid, M., and Haleem, A. (2019). 4D printing applications in medical field: a brief review. Clin. Epidemiol. Glob. Health 7, 317-321. doi: 10.1016/j.cegh.2018.09.007

Ji, C., Annabi, N., Hosseinkhani, M., Sivaloganathan, S., and Dehghani, F. (2012). Fabrication of poly-DL-lactide/polyethylene glycol scaffolds using the gas foaming technique. Acta Biomater. 8, 570-578. doi: 10.1016/j.actbio.2011.09.028

Jiang, S. D., Yao, Q. Z., Ma, Y. F., Zhou, G. T., and Fu, S. Q. (2015). Phosphatedependent morphological evolution of hydroxyapatite and implication for biomineralisation. Gondwana Res. 28, 858-868. doi: 10.1016/j.gr.2014.04.005

Jones, N. (2012). Science in three dimensions: the print revolution. Nat. News 487 , 22-23. doi: $10.1038 / 487022$ a

Jun, S.-H., Lee, E.-J., Jang, T.-S., Kim, H.-E., Jang, J.-H., and Koh, Y.H. (2013). Bone morphogenic protein-2 (BMP-2) loaded hybrid coating on porous hydroxyapatite scaffolds for bone tissue engineering. J. Mater. Sci. Mater. Med. 24, 773-782. doi: 10.1007/s10856-012$4822-0$

Kargozar, S., Baino, F., Hamzehlou, S., Hill, R. G., and Mozafari, M. (2018a). Bioactive glasses entering the mainstream. Drug Discov. Today 23, 1700-1704. doi: 10.1016/j.drudis.2018.05.027

Kargozar, S., Hamzehlou, S., and Baino, F. (2018b). "Effects of the biological environment on ceramics: Degradation, cell response, and in vivo behavior," in Fundamental Biomaterials: Ceramics, eds S. Thomas, P. Balakrishna, and M. S. Sree Kala (Duxford: Woodhead Publishing), 407-437. doi: 10.1016/B978-0-08-102203-0.00014-7

Kargozar, S., Montazerian, M., Hamzehlou, S., Kim, H. W., and Baino, F. (2018c). Mesoporous bioactive glasses (MBGs): promising platforms for antibacterial strategies. Acta Biomater. 81, 1-19. doi: 10.1016/j.actbio.2018. 09.052

Kaur, G., Kumar, V., Baino, F., Mauro, J. C., Pickrell, G., Evans, I., et al. (2019). Mechanical properties of bioactive glasses, ceramics, glass-ceramics and composites: state-of-the-art review and future challenges. Mater. Sci. Eng. C 104:109895. doi: 10.1016/j.msec.2019.109895

Khalil, S., and Sun, W. (2007). Biopolymer deposition for freeform fabrication of hydrogel tissue constructs. Mater. Sci. Eng. C 27, 469-478. doi: 10.1016/j.msec.2006.05.023

Khalyfa, A., Vogt, S., Weisser, J., Grimm, G., Rechtenbach, A., Meyer, W., et al. (2007). Development of a new calcium phosphate powder-binder system for the 3D printing of patient specific implants. J. Mater. Sci. Mater. Med. 18, 909-916. doi: 10.1007/s10856-006-0073-2

Kim, J., McBride, S., Tellis, B., Alvarez-Urena, P., Song, Y.-H., Dean, D. D., et al. (2012). Rapid-prototyped PLGA/ $\beta$-TCP/hydroxyapatite nanocomposite scaffolds in a rabbit femoral defect model. Biofabrication 4:025003. doi: $10.1088 / 1758-5082 / 4 / 2 / 025003$

Kim, K., Lee, C. H., Kim, B. K., and Mao, J. J. (2010). Anatomically shaped tooth and periodontal regeneration by cell homing. J. Dent. Res. 89, 842-847. doi: $10.1177 / 0022034510370803$

Kim, M. H., Yun, C., Chalisserry, E. P., Lee, Y. W., Kang, H. W., Park, S. H., et al. (2018). Quantitative analysis of the role of nanohydroxyapatite (nHA) on 3D-printed PCL/nHA composite scaffolds. Mater. Lett. 220, 112-115. doi: 10.1016/j.matlet.2018.03.025 
Kolmas, J., Krukowski, S., Laskus, A., and Jurkitewicz, M. (2016). Synthetic hydroxyapatite in pharmaceutical applications. Ceram. Int. 42, 2472-2487. doi: 10.1016/j.ceramint.2015.10.048

Koski, C., Onuike, B., Bandyopadhyay, A., and Bose, S. (2018). Starchhydroxyapatite composite bone scaffold fabrication utilizing a slurry extrusion-based solid freeform fabricator. Addit. Manuf. 24, 47-59. doi: 10.1016/j.addma.2018.08.030

Krishnakumar, G. S., Gostynska, N., Dapporto, M., Campodoni, E., Montesi, M., Panseri, S., et al. (2018). Evaluation of different crosslinking agents on hybrid biomimetic collagen-hydroxyapatite composites for regenerative medicine. Int. J. Biol. Macromol. 106, 739-748. doi: 10.1016/j.ijbiomac.2017.08.076

Kruth, J. P. (1991). Material incress manufacturing by rapid prototyping techniques. CIRP Ann. 40, 603-614. doi: 10.1016/S0007-8506(07)61136-6

Kumar, A., Akkineni, A. R., Basu, B., and Gelinsky, M. (2016b). Three-dimensional plotted hydroxyapatite scaffolds with predefined architecture: comparison of stabilization by alginate cross-linking versus sintering. J. Biomater. Appl. 30, 1168-1181. doi: $10.1177 / 0885328215617058$

Kumar, A., Madhusudana Rao, K., Haider, A., Han, S. S., Son, T. W., Kim, J. H., et al. (2017a). Fabrication and characterization of multicomponent polysaccharide/nanohydroxyapatite composite scaffolds. Polym. Plast. Technol. Eng. 56, 983-991. doi: 10.1080/03602559.2016.1247279

Kumar, A., Negi, Y. S., Choudhary, V., and Bhardwaj, N. K. (2014). Microstructural and mechanical properties of porous biocomposite scaffolds based on polyvinyl alcohol, nano-hydroxyapatite and cellulose nanocrystals. Cellulose 21:3409. doi: 10.1007/s10570-014-0339-7

Kumar, A., Negi, Y. S., Choudhary, V., and Bhardwaj, N. K. (2016a). Fabrication of poly (vinyl alcohol)/ovalbumin/cellulose nanocrystals/nanohydroxyapatite based biocomposite scaffolds. Int. J. Polym. Mater. Polym. Biomater. 65, 191-201. doi: 10.1080/00914037.2015.1099102

Kumar, A., Nune, K. C., and Misra, R. D. K. (2016c). Biological functionality of extracellular matrix-ornamented three-dimensional printed hydroxyapatite scaffolds. J. Biomed. Mater. Res. Part A 104, 1343-1351. doi: $10.1002 /$ jbm.a.35664

Kumar, A., Rao, K. M., and Han, S. S. (2017b). Synthesis of mechanically stiff and bioactive hybrid hydrogels for bone tissue engineering applications. Chem. Eng. J. 317, 119-131. doi: 10.1016/j.cej.2017.02.065

Kumar, A., Rao, K. M., and Han, S. S. (2018). Mechanically viscoelastic nanoreinforced hybrid hydrogels composed of polyacrylamide, sodium carboxymethylcellulose, graphene oxide, and cellulose nanocrystals. Carbohydr. Polym. 193, 228-238. doi: 10.1016/j.carbpol.2018.04.004

Kumar, A., Rao, K. M., Kwon, S. E., Lee, Y. N., and Han, S. S. (2017c). Xanthan gum/bioactive silica glass hybrid scaffolds reinforced with cellulose nanocrystals: morphological, mechanical and in vitro cytocompatibility study. Mater. Lett. 193, 274-278. doi: 10.1016/j.matlet.2017.01.143

Kumar, A., Zo, S. M., Kim, J. H., Kim, S. C., and Han, S. S. (2019). Enhanced physical, mechanical, and cytocompatibility behavior of polyelectrolyte complex hydrogels by reinforcing halloysite nanotubes and graphene oxide. Compos. Sci. Technol. 175, 35-45. doi: 10.1016/j.compscitech.2019.03.008

Kuss, M. A., Harms, R., Wu, S., Wang, Y., Untrauer, J. B., Carlson, M. A., et al. (2017). Short-term hypoxic preconditioning promotes prevascularization in 3D bioprinted bone constructs with stromal vascular fraction derived cells. RSC Adv. 7, 29312-29320. doi: 10.1039/C7RA04372D

Law, N., Doney, B., Glover, H., Qin, Y., Aman, Z. M., Sercombe, T. B., et al. (2018). Journal of the mechanical behavior of biomedical materials characterisation of hyaluronic acid methylcellulose hydrogels for 3D bioprinting. J. Mech. Behav. Biomed. Mater. 77, 389-399. doi: 10.1016/j.jmbbm.2017.09.031

Lazić, V., Smičiklas, I., Marković, J., Lončarević, D., Dostanić, J., Ahrenkiel, S. P., et al. (2018). Antibacterial ability of supported silver nanoparticles by functionalized hydroxyapatite with 5-aminosalicylic acid. Vacuum 148, 62-68. doi: 10.1016/j.vacuum.2017.10.039

Lee, J. W., Ahn, G., Kim, D. S., and Cho, D. W. (2009). Development of nano-and microscale composite 3D scaffolds using PPF/DEFHA and micro-stereolithography. Microelectron. Eng. 86, 1465-1467. doi: $10.1016 /$ j.mee.2008.12.038

LeGeros, R. Z. (2002). Properties of osteoconductive biomaterials: calcium phosphates. Clin. Orthop. Relat. Res. 395, 81-98. doi: 10.1097/00003086-200202000-00009
Leprêtre, S., Chai, F., Hornez, J. C., Vermet, G., Neut, C., Descamps, M., et al. (2009). Prolonged local antibiotics delivery from hydroxyapatite functionalised with cyclodextrin polymers. Biomaterials 30, 6086-6093. doi: 10.1016/j.biomaterials.2009.07.045

Leukers, B., Gülkan, H., Irsen, S. H., Milz, S., Tille, C., Schieker, M., et al. (2005). Hydroxyapatite scaffolds for bone tissue engineering made by $3 \mathrm{D}$ printing. $J$. Mater. Sci. Mater. Med. 16, 1121-1124. doi: 10.1007/s10856-005-4716-5

Li, H., Sun, X., Li, Y., Li, B., Liang, C., and Wang, H. (2019). Preparation and properties of carbon nanotube $(\mathrm{Fe}) /$ hydroxyapatite composite as magnetic targeted drug delivery carrier. Mater. Sci. Eng. C 97, 222-229. doi: $10.1016 /$ j.msec.2018.11.042

Li, N., Wu, G., Yao, H., Tang, R., Gu, X., and Tu, C. (2019). Size effect of nano-hydroxyapatite on proliferation of odontoblast-like MDPC-23 cells. Dent. Mater. J. 38, 534-539. doi: 10.4012/dmj.2018-155

Li, Q., Lei, X., Wang, X., Cai, Z., Lyu, P., and Zhang, G. (2019). Hydroxyapatite/collagen three-dimensional printed scaffolds and their osteogenic effects on human bone marrow-derived mesenchymal stem cells. Tissue Eng. Part A 25, 1261-71. doi: 10.1089/ten.tea.2018.0201

Li, Y.-C., Zhang, Y. S., Akpek, A., Shin, S. R., and Khademhosseini, A. (2016). 4D bioprinting: the next-generation technology for biofabrication enabled by stimuli-responsive materials. Biofabrication 9:012001. doi: 10.1088/1758-5090/9/1/012001

Lin, K., Wu, C., and Chang, J. (2014). Advances in synthesis of calcium phosphate crystals with controlled size and shape. Acta Biomater. 10, 4071-4102. doi: 10.1016/j.actbio.2014.06.017

Liu, A., Xue, G. H., Sun, M., Shao, H. F., Ma, C. Y., Gao, Q., et al. (2016). 3D printing surgical implants at the clinic: a experimental study on anterior cruciate ligament reconstruction. Sci. Rep. 6:21704. doi: 10.1038/srep21704

Liu, D., Nie, W., Li, D., Wang, W., Zheng, L., Zhang, J., et al. (2019). 3D printed PCL/SrHA scaffold for enhanced bone regeneration. Chem. Eng. J. 362, 269-279. doi: 10.1016/j.cej.2019.01.015

Liu, J., Li, L., Suo, H., Yan, M., Yin, J., and Fu, J. (2019). 3D printing of biomimetic multi-layered GelMA/nHA scaffold for osteochondral defect repair. Mater. Des. 171:107708. doi: 10.1016/j.matdes.2019.107708

Liu, Q., Huang, S., Matinlinna, J. P., Chen, Z., and Pan, H. (2013). Insight into biological apatite: physiochemical properties and preparation approaches. Biomed Res. Int. 2013, 1-13. doi: 10.1155/2013/929748

Liu, Y. S., Sow, W. T., Tan, L. P., Wu, Y., Lai, Y., and Li, H. (2019). 4D printing and stimuli-responsive materials in biomedical aspects. Acta Biomater. 92, 19-36. doi: 10.1016/j.actbio.2019.05.005

Liu, Z., Liang, H., Shi, T., Xie, D., Chen, R., Han, X., et al. (2019). Additive manufacturing of hydroxyapatite bone scaffolds via digital light processing and in vitro compatibility. Ceram. Int. 45, 11079-11086. doi: 10.1016/j.ceramint.2019.02.195

Luo, Y., Chen, S., Shi, Y., and Ma, J. (2018). 3D printing of strontium-doped hydroxyapatite based composite scaffolds for repairing critical-sized rabbit calvarial defects. Biomed. Mater. 13:065004. doi: 10.1088/1748-605X/aad923

Malda, J., Visser, J., Melchels, F. P., Jüngst, T., Hennink, W. E., Dhert, W. J. A., et al. (2013). 25th anniversary article: engineering hydrogels for biofabrication. $A d v$. Mater. Weinheim. 25, 5011-5028. doi: 10.1002/adma.201302042

Maroulakos, M., Kamperos, G., Tayebi, L., and Halazonetis, D. (2019). Applications of 3D printing on craniofacial bone repair: a systematic review. J. Dent. 80, 1-14. doi: 10.1016/j.jdent.2018.11.004

Martínez-Vázquez, F. J., Cabañas, M. V., Paris, J. L., Lozano, D., and Vallet-Regí, M. (2015). Fabrication of novel Si-doped hydroxyapatite/gelatine scaffolds by rapid prototyping for drug delivery and bone regeneration. Acta Biomater. 15, 200-209. doi: 10.1016/j.actbio.2014.12.021

Minardi, S., Taraballi, F., Cabrera, F. J., Van Eps, J., Wang, X., Gazze, S. A., et al. (2019). Biomimetic hydroxyapatite/collagen composite drives bone niche recapitulation in a rabbit orthotopic model. Mater. Today Bio. 2:100005. doi: $10.1016 /$ j.mtbio.2019.100005

Mondal, S., Dorozhkin, S. V., and Pal, U. (2018). Recent progress on fabrication and drug delivery applications of nanostructured hydroxyapatite. Wiley Interdiscip. Rev. Nanomed. Nanobiotechnol. 10:e1504. doi: 10.1002/wnan.1504

Moreau, J. L., Caccamese, J. F., Coletti, D. P., Sauk, J. J., and Fisher, J. P. (2007) Tissue engineering solutions for cleft palates. J. Oral Maxillofac. Surg. 65, 2503-2511. doi: 10.1016/j.joms.2007.06.648 
Motealleh, A., Eqtesadi, S., Pajares, A., Miranda, P., Salamon, D., and Castkova, K. (2017). Case study: reinforcement of $45 S 5$ bioglass robocast scaffolds by HA/PCL nanocomposite coatings. J. Mech. Behav. Biomed. Mater. 75, 114-118. doi: 10.1016/j.jmbbm.2017.07.012

Nandakumar, A., Fernandes, H., de Boer, J., Moroni, L., Habibovic, P., and van Blitterswijk, C. A. (2010). Fabrication of bioactive composite scaffolds by electrospinning for bone regeneration. Macromol. Biosci. 10, 1365-1373. doi: 10.1002/mabi.201000145

Neufurth, M., Wang, X., Wang, S., Steffen, R., Ackermann, M., Haep, N. D., et al. (2017). 3D printing of hybrid biomaterials for bone tissue engineering: Calcium-polyphosphate microparticles encapsulated by polycaprolactone. Acta Biomater. 64, 377-388. doi: 10.1016/j.actbio.2017.09.031

Nyberg, E., Rindone, A., Dorafshar, A., and Grayson, W. L. (2017). Comparison of 3D-printed Poly- $\varepsilon$-caprolactone scaffolds functionalized with tricalcium phosphate, hydroxyapatite, bio-oss, or decellularized bone matrix. Tissue Eng. Part A 23, 503-514. doi: 10.1089/ten.tea.2016.0418

Oladapo, B. I., Zahedi, S. A., and Adeoye, A. O. M. (2019). 3D printing of bone scaffolds with hybrid biomaterials. Compos. Part B Eng. 158, 428-436. doi: 10.1016/j.compositesb.2018.09.065

Ozbolat, I. T., and Hospodiuk, M. (2016). Current advances and future perspectives in extrusion-based bioprinting. Biomaterials 76, 321-343. doi: 10.1016/j.biomaterials.2015.10.076

Pandey, A., Midha, S., Sharma, R. K., Maurya, R., Nigam, V. K., Ghosh, S., et al. (2018). Antioxidant and antibacterial hydroxyapatite-based biocomposite for orthopedic applications. Mater. Sci. Eng. C 88, 13-24. doi: 10.1016/j.msec.2018.02.014

Park, S. A., Lee, S. H., and Kim, W. D. (2011). Fabrication of porous polycaprolactone/hydroxyapatite (PCL/HA) blend scaffolds using a 3D plotting system for bone tissue engineering. Bioproc. Biosyst. Eng. 34, 505-513. doi: 10.1007/s00449-010-0499-2

Pei, X., Ma, L., Zhang, B., Sun, J., Sun, Y., Fan, Y., et al. (2017). Creating hierarchical porosity hydroxyapatite scaffolds with osteoinduction by threedimensional printing and microwave sintering. Biofabrication 9:045008. doi: 10.1088/1758-5090/aa90ed

Porter, A., Patel, N., Brooks, R., Best, S., Rushton, N., and Bonfield, W. (2005). Effect of carbonate substitution on the ultrastructural characteristics of hydroxyapatite implants. J. Mater. Sci. Mater. Med. 16, 899-907. doi: 10.1007/s10856-005-4424-1

Ramesh, N., Moratti, S. C., and Dias, G. J. (2018). Hydroxyapatite-polymer biocomposites for bone regeneration: a review of current trends. J. Biomed. Mater. Res. Part B Appl. Biomater. 106, 2046-2057. doi: 10.1002/jbm.b.33950

Ribeiro, N., Sousa, S. R., and Monteiro, F. J. (2010). Influence of crystallite size of nanophased hydroxyapatite on fibronectin and osteonectin adsorption and on MC3T3-E1 osteoblast adhesion and morphology. J. Colloid Interface Sci. 351, 398-406. doi: 10.1016/j.jcis.2010.08.013

Roh, H. S., Jung, S. C., Kook, M. S., and Kim, B. H. (2016). In vitro study of 3D PLGA/n-HAp/ $\beta$-TCP composite scaffolds with etched oxygen plasma surface modification in bone tissue engineering. Appl. Surf. Sci. 388, 321-330. doi: 10.1016/j.apsusc.2015.12.243

Roh, H. S., Lee, C. M., Hwang, Y. H., Kook, M. S., Yang, S. W., Lee, D., et al. (2017). Addition of $\mathrm{MgO}$ nanoparticles and plasma surface treatment of threedimensional printed polycaprolactone/hydroxyapatite scaffolds for improving bone. Mater. Sci. Eng. C 74, 525-535. doi: 10.1016/j.msec.2016.12.054

Rokusek, D., Davitt, C., Bandyopadhyay, A., Bose, S., and Hosick, H. L. (2005). Interaction of human osteoblasts with bioinert and bioactive ceramic substrates. J. Biomed. Mater. Res. Part A 75A, 588-594. doi: 10.1002/jbm.a.30459

Roleček, J., Pejchalová, L., Martínez-Vázquez, F. J., González, P. M., and Salamon, D. (2019). Bioceramic scaffolds fabrication: indirect 3D printing combined with ice-templating vs. robocasting. J. Eur. Ceram. Soc. 39, 1595-1602. doi: 10.1016/j.jeurceramsoc.2018.12.006

Ronca, A., Ambrosio, L., and Grijpma, D. W. (2013). Preparation of designed poly (D, L-lactide)/nanosized hydroxyapatite composite structures by stereolithography. Acta Biomater. 9, 5989-5996. doi: 10.1016/j.actbio.2012.12.004

Ruffini, A., Sprio, S., and Tampieri, A. (2013). Study of the hydrothermal transformation of wood-derived calcium carbonate into 3D hierarchically organized hydroxyapatite. Chem. Eng. J. 217, 150-158. doi: 10.1016/j.cej.2012.11.107

Russias, J., Saiz, E., Deville, S., Gryn, K., Liu, G., Nalla, R. K., et al. (2007). Fabrication and in vitro characterization of three-dimensional organic/inorganic scaffolds by robocasting. J. Biomed. Mater. Res. Part A 83A, 434-445. doi: 10.1002/jbm.a.31237

Sadat-Shojai, M., Khorasani, M. T., Dinpanah-Khoshdargi, E., and Jamshidi, A. (2013). Synthesis methods for nanosized hydroxyapatite with diverse structures. Acta Biomater. 9, 7591-7621. doi: 10.1016/j.actbio.2013.04.012

Safi, S., Karimzadeh, F., and Labbaf, S. (2018). Mesoporous and hollow hydroxyapatite nanostructured particles as a drug delivery vehicle for the local release of ibuprofen. Mater. Sci. Eng. C 92, 712-719. doi: 10.1016/j.msec.2018.07.004

Sahithi, K., Swetha, M., Prabaharan, M., Moorthi, A., Saranya, N., Ramasamy, K., et al. (2010). Synthesis and characterization of nanoscalehydroxyapatitecopper for antimicrobial activity towards bone tissue engineering applications. J. Biomed. Nanotechnol. 6, 333-339. doi: 10.1166/jbn.2010.1138

Samani, S., Hossainalipour, S. M., Tamizifar, M., and Rezaie, H. R. (2013). In vitro antibacterial evaluation of sol-gel-derived $\mathrm{Zn}$-, Ag-, and $(\mathrm{Zn}+\mathrm{Ag})$-doped hydroxyapatite coatings against methicillin-resistant Staphylococcus aureus. J. Biomed. Mater. Res. Part A 101A, 222-230. doi: 10.1002/jbm.a.34322

San Thian, E., Huang, J., Best, S. M., Barber, Z. H., Brooks, R. A., Rushton, N., et al. (2006). The response of osteoblasts to nanocrystalline silicon-substituted hydroxyapatite thin films. Biomaterials 27, 2692-2698. doi: 10.1016/j.biomaterials.2005.12.019

Sarda, S., Errassifi, F., Marsan, O., Geffre, A., Trumel, C., and Drouet, C. (2016). Adsorption of tranexamic acid on hydroxyapatite: toward the development of biomaterials with local hemostatic activity. Mater. Sci. Eng. C 66, 1-7. doi: 10.1016/j.msec.2016.04.032

Sasaki, G., Watanabe, Y., Miyamoto, W., Yasui, Y., Morimoto, S., and Kawano, H. (2018). Induced membrane technique using beta-tricalcium phosphate for reconstruction of femoral and tibial segmental bone loss due to infection: technical tips and preliminary clinical results. Int. Orthop. 42, 17-24. doi: $10.1007 /$ s00264-017-3503-5

Saunders, R. E., Gough, J. E., and Derby, B. (2008). Delivery of human fibroblast cells by piezoelectric drop-on-demand inkjet printing. Biomaterials 29, 193-203. doi: 10.1016/j.biomaterials.2007.09.032

Senatov, F. S., Niaza, K. V., Zadorozhnyy, M. Y., Maksimkin, A. V., Kaloshkin, S. D., and Estrin, Y. Z. (2016). Mechanical properties and shape memory effect of 3D-printed PLA-based porous scaffolds. J. Mech. Behav. Biomed. Mater. 57, 139-148. doi: 10.1016/j.jmbbm.2015.11.036

Sha, J., Kanno, T., Miyamoto, K., Bai, Y., Hideshima, K., and Matsuzaki, Y. (2019). Application of a bioactive/bioresorbable three-dimensional porous uncalcined and unsintered hydroxyapatite/poly-d/l-lactide composite with human mesenchymal stem cells for bone regeneration in maxillofacial surgery: a pilot animal study. Materials 12:705. doi: 10.3390/ma12050705

Shao, H., He, J., Lin, T., Zhang, Z., Zhang, Y., and Liu, S. (2019). 3D gel-printing of hydroxyapatite scaffold for bone tissue engineering. Ceram. Int. 45, 1163-1170. doi: 10.1016/j.ceramint.2018.09.300

Shuai, C., Gao, C., Nie, Y., Hu, H., Zhou, Y., and Peng, S. (2011). Structure and properties of nano-hydroxypatite scaffolds for bone tissue engineering with a selective laser sintering system. Nanotechnology 22:285703. doi: 10.1088/0957-4484/22/28/285703

Singh, S., and Ramakrishna, S. (2017). Biomedical applications of additive manufacturing: present and future. Curr. Opin. Biomed. Eng. 2, 105-115. doi: 10.1016/j.cobme.2017.05.006

Sprio, S., Preti, L., Montesi, M., Panseri, S., Adamiano, A., Vandini, A., et al. (2019). Surface phenomena enhancing the antibacterial and osteogenic ability of nanocrystalline hydroxyapatite, activated by multiple ions doping. ACS Biomater. Sci. Eng. 5, 5947-5959. doi: 10.1021/acsbiomaterials.9b00893

Suh, S. W., Shin, J. Y., Kim, J., Kim, J., Beak, C. H., Kim, D. I., et al. (2002). Effect of different particles on cell proliferation in polymer scaffolds using a solvent-casting and particulate leaching technique. ASAIO J. 48, 460-464. doi: 10.1097/00002480-200209000-0 0003

Sui, T., Salvati, E., Zhang, H., Nyaza, K., Senatov, F. S., Salimon, A. I., et al. (2019). Probing the complex thermo-mechanical properties of a 
3D-printed polylactide-hydroxyapatite composite using in situ synchrotron X-ray scattering. J. Adv. Res. 16, 113-122. doi: 10.1016/j.jare.2018.11.002

Sumer, M., Keles, G. C., Cetinkaya, B. O., Balli, U., Pamuk, F., and Uckan, S. (2013). Autogenous cortical bone and bioactive glass grafting for treatment of intraosseous periodontal defects. Eur. J. Dent. 7, 6-14. doi: 10.1055/s-009-44516

Sundarabharathi, L., Chinnaswamy, M., Ponnamma, D., Parangusan, H., and AlMaadeed, M. A. A. (2019). Investigation of antimicrobial properties and in-vitro bioactivity of Ce3+-Sr2+dual-substituted nano hydroxyapatites. J. Am. Ceram. Soc. 102, 144-157. doi: 10.1111/jace.15866

Suvannapruk, W., and Suwanprateeb, J. (2018). "Properties alteration of antituberculosis drugs loaded 3D printed hydroxyapatite by polycaprolactone coating," in Key Engineering Materials, Vol. 766. eds S. Sirisoonthorn, S. Jiemsirilers, T. Wasanapiarnpong, N. Chuankrerkkul, R. Pornprasertsuk, N. Traiphol, and P. Sujaridworakun (Stafa-Zurich: Trans Tech Publications), 94-98. doi: 10.4028/www.scientific.net/KEM.766.94

Suvannapruk, W., Thammarakcharoen, F., Phanpiriya, P., and Suwanprateeb, J. (2013). Development of antibiotics impregnated nanosized silver phosphate-doped hydroxyapatite bone graft. J. Nanomater. 2013:542584. doi: 10.1155/2013/542584

Suwanprateeb, J., Sanngam, R., Suvannapruk, W., and Panyathanmaporn, T. (2009). Mechanical and in vitro performance of apatite-wollastonite glass ceramic reinforced hydroxyapatite composite fabricated by 3Dprinting. J. Mater. Sci. Mater. Med. 20, 1281-1289. doi: 10.1007/s10856-0093697-1

Syamchand, S. S., and Sony, G. (2015). Multifunctional hydroxyapatite nanoparticles for drug delivery and multimodal molecular imaging. Microchim. Acta 182, 1567-1589. doi: 10.1007/s00604-015-1504-x

Szcześ, A., Szcześ, A., Hołysz, L., and Chibowski, E. (2017). Synthesis of hydroxyapatite for biomedical applications. Adv. Colloid Interface Sci. 249, 321-330. doi: 10.1016/j.cis.2017.04.007

Tampieri, A., Sprio, S., Ruffini, A., Celotti, G., Lesci, I. G., and Roveri, N. (2009). From wood to bone: multi-step process to convert wood hierarchical structures into biomimetic hydroxyapatite scaffolds for bone tissue engineering. J. Mater. Chem. 19, 4973-4980. doi: 10.1039/b900333a

Touri, M., Moztarzadeh, F., Osman, N. A. A., Dehghan, M. M., and Mozafari, M. (2018). 3D-printed biphasic calcium phosphate scaffolds coated with an oxygen generating system for enhancing engineered tissue survival. Mater. Sci. Eng. C 84, 236-242. doi: 10.1016/j.msec.2017.11.037

Trachtenberg, J. E., Placone, J. K., Smith, B. T., Fisher, J. P., and Mikos, A. G. (2017). Extrusion-based 3D printing of poly(propylene fumarate) scaffolds with hydroxyapatite gradients. J. Biomater. Sci. Polym. Ed. 28, 532-554. doi: 10.1080/09205063.2017.1286184

Trachtenberg, J. E., Placone, J. K., Smith, B. T., Piard, C. M., Santoro, M., Scott, D. W., et al. (2016). Extrusion-based 3D printing of poly(propylene fumarate) in a full-factorial design. ACS Biomater. Sci. Eng. 2, 1771-1780. doi: 10.1021/acsbiomaterials.6b00026

Vella, J. B., Trombetta, R. P., Hoffman, M. D., Inzana, J., Awad, H., and Benoit, D. S. W. (2018). Three dimensional printed calcium phosphate and poly(caprolactone) composites with improved mechanical properties and preserved microstructure. J. Biomed. Mater. Res. Part A 106, 663-672. doi: $10.1002 /$ jbm.a. 36270

Vu, A. A., Robertson, S. F., Ke, D., Bandyopadhyay, A., and Bose, S. (2019). Mechanical and biological properties of $\mathrm{ZnO}, \mathrm{SiO}$, and $\mathrm{Ag} 2 \mathrm{O}$ doped plasma sprayed hydroxyapatite coating for orthopaedic and dental applications. Acta Biomater. 92, 325-335. doi: 10.1016/j.actbio.2019.05.020

Wang, H., Wu, G., Zhang, J., Zhou, K., Yin, B., Su, X., et al. (2016). Osteogenic effect of controlled released rhBMP-2 in $3 \mathrm{D}$ printed porous hydroxyapatite scaffold. Colloids Surfaces B Biointerfaces 141, 491-498. doi: 10.1016/j.colsurfb.2016.02.007

Wang, Q., Li, P., Tang, P., Ge, X., Ren, F., Zhao, C., et al. (2019). Experimental and simulation studies of strontium/fluoride-codoped hydroxyapatite nanoparticles with osteogenic and antibacterial activities. Colloids Surfaces $B$ Biointerfaces 182:110359. doi: 10.1016/j.colsurfb.2019.110359

Wang, X., Molino, B. Z., Pitkänen, S., Ojansivu, M., Xu, C., Hannula, M., et al. (2019). 3D scaffolds of polycaprolactone/copper-doped bioactive glass: architecture engineering with additive manufacturing and cellular assessments in a coculture of bone marrow stem cells and endothelial cells. ACS Biomater. Sci. Eng. 5, 4496-4510. doi: 10.1021/acsbiomaterials.9b00105
Water, J. J., Bohr, A., Boetker, J., Aho, J., Sandler, N., Nielsen, H. M., et al. (2015). Three-dimensional printing of drug-eluting implants: preparation of an antimicrobial polylactide feedstock material. J. Pharm. Sci. 104, 1099-1107. doi: 10.1002/jps.24305

Woesz, A., and Best, S. M. (2009). "Cellular Response to Bioceramics," in Cellular Response to Biomaterials, ed. L. Di Silvio (Woodhead Publ.), 136-155. doi: $10.1533 / 9781845695477.1 .136$

Wu, C., Fan, W., Zhou, Y., Luo, Y., Gelinsky, M., Chang, J., et al. (2012). 3D-printing of highly uniform $\mathrm{CaSiO} 3$ ceramic scaffolds: preparation, characterization and in vivo osteogenesis. J. Mater. Chem. 22, 12288-12295. doi: $10.1039 / \mathrm{c} 2 \mathrm{jm} 30566 \mathrm{f}$

Wu, V. M., Tang, S., and Uskoković, V. (2018). Calcium phosphate nanoparticles as intrinsic inorganic antimicrobials: the antibacterial effect. ACS Appl. Mater. Interfaces 10, 34013-34028. doi: 10.1021/acsami. $8 \mathrm{~b} 12784$

Wu, X., Liu, Y., Li, X., Wen, P., Zhang, Y., Long, Y., et al. (2010). Preparation of aligned porous gelatin scaffolds by unidirectional freezedrying method. Acta Biomater. 6, 1167-1177. doi: 10.1016/j.actbio.2009. 08.041

Xia, Y., Zhou, P., Cheng, X., Xie, Y., Liang, C., Li, C., et al. (2013). Selective laser sintering fabrication of nano-hydroxyapatite/poly- $\varepsilon$-caprolactone scaffolds for bone tissue engineering applications. Int. J. Nanomedicine 8, 4197-4213. doi: $10.2147 /$ IJN.S50685

Xiao, Q., Zhou, K., Chen, C., Jiang, M., Zhang, Y., Luo, H., et al. (2016). Hollow and porous hydroxyapatite microspheres prepared with an $\mathrm{O} / \mathrm{W}$ emulsion by spray freezing method. Mater. Sci. Eng. C 69, 1068-1074. doi: 10.1016/j.msec.2016.07.082

Xiao, W., Bal, B. S., and Rahaman, M. N. (2016). Preparation of resorbable carbonate-substituted hollow hydroxyapatite microspheres and their evaluation in osseous defects in vivo. Mater. Sci. Eng. C 60, 324-332. doi: 10.1016/j.msec.2015.11.039

Xu, S., Lin, K., Wang, Z., Chang, J., Wang, L., Lu, J., et al. (2008). Reconstruction of calvarial defect of rabbits using porous calcium silicate bioactive ceramics. Biomaterials 29, 2588-2596. doi: 10.1016/j.biomaterials.2008.03.013

Yang, C., Wang, X., Ma, B., Zhu, H., Huan, Z., Ma, N., et al. (2017). 3Dprinted bioactive $\mathrm{Ca}_{3} \mathrm{SiO}{ }_{5}$ bone cement scaffolds with nano surface structure for bone regeneration. ACS Appl. Mater. Interfaces 9, 5757-5767. doi: $10.1021 /$ acsami.6b14297

Yang, Y., Yang, S., Wang, Y., Yu, Z., Ao, H., Zhang, H., et al. (2016). Anti-infective efficacy, cytocompatibility and biocompatibility of a 3D-printed osteoconductive composite scaffold functionalized with quaternized chitosan. Acta Biomater. 46, 112-128. doi: 10.1016/j.actbio.2016. 09.035

Yao, Q., Wei, B., Guo, Y., Jin, C., Du, X., Yan, C., et al. (2015). Design, construction and mechanical testing of digital 3D anatomical data-based PCLHA bone tissue engineering scaffold. J. Mater. Sci. Mater. Med. 26:5360. doi: 10.1007/s10856-014-5360-8

Yilmaz, B., Alshemary, A. Z., and Evis, Z. (2018). Co-doped hydroxyapatites as potential materials for biomedical applications. Microchem. J. 144, 443-453. doi: 10.1016/j.microc.2018.10.007

Yu, J., Chu, X., Cai, Y., Tong, P., and Yao, J. (2014). Preparation and characterization of antimicrobial nano-hydroxyapatite composites. Mater. Sci. Eng. C 37, 54-59. doi: 10.1016/j.msec.2013.12.038

Zeng, Y., Yan, Y., Yan, H., Liu, C., Li, P., Dong, P., et al. (2018). 3D printing of hydroxyapatite scaffolds with good mechanical and biocompatible properties by digital light processing. J. Mater. Sci. 53, 6291-6301. doi: 10.1007/s10853-018-1992-2

Zhang, B., Pei, X., Song, P., Sun, H., Li, H., Fan, Y., et al. (2018), Porous bioceramics produced by inkjet $3 \mathrm{D}$ printing: effect of printing ink formulation on the ceramic macro and micro porous architectures control. Compos. Part B Eng. 155, 112-121. doi: 10.1016/j.compositesb.2018. 08.047

Zhang, L., Yang, G., Johnson, B. N., and Jia, X. (2019). Three-dimensional (3D) printed scaffold and material selection for bone repair. Acta Biomater. 84, 16-33. doi: 10.1016/j.actbio.2018.11.039

Zhao, Q., Wang, T., Wang, J., Zheng, L., Jiang, T., Cheng, G., et al. (2011). Template-directed hydrothermal synthesis of hydroxyapatite as a drug delivery system for the poorly water-soluble drug carvedilol. 
Appl. Surf. Sci. 257, 10126-10133. doi: 10.1016/j.apsusc.2011. 06.161

Zheng, P., Yao, Q., Mao, F., Liu, N., Xu, Y., Wei, B., et al. (2017). Adhesion, proliferation and osteogenic differentiation of mesenchymal stem cells in $3 \mathrm{D}$ printed poly- $\varepsilon$-caprolactone/hydroxyapatite scaffolds combined with bone marrow clots. Mol. Med. Rep. 16, 5078-5084. doi: 10.3892/mmr.2017.7266

Zhou, K., Zhang, X., Chen, Z., Shi, L., and Li, W. (2015). Preparation and characterization of hydroxyapatite-sodium alginate scaffolds by extrusion freeforming. Ceram. Int. 41, 14029-14034. doi: 10.1016/j.ceramint.2015.07.016

Zhou, Y., Wu, C., and Chang, J. (2019). Bioceramics to regulate stem cells and their microenvironment for tissue regeneration. Mater. Today 24, 41-56. doi: 10.1016/j.mattod.2018.07.016

Zhou, Z., Buchanan, F., Mitchell, C., and Dunne, N. (2014). Printability of calcium phosphate: calcium sulfate powders for the application of tissue engineered bone scaffolds using the 3D printing technique. Mater. Sci. Eng. C 38, 1-10. doi: 10.1016/j.msec.2014.01.027

Conflict of Interest: The authors declare that the research was conducted in the absence of any commercial or financial relationships that could be construed as a potential conflict of interest.

Copyright (c) 2019 Kumar, Kargozar, Baino and Han. This is an open-access article distributed under the terms of the Creative Commons Attribution License (CC BY).

The use, distribution or reproduction in other forums is permitted, provided the original author(s) and the copyright owner(s) are credited and that the original publication in this journal is cited, in accordance with accepted academic practice. No use, distribution or reproduction is permitted which does not comply with these terms. 